\title{
Long-term assessment of power capacity incentives by modeling generation investment dynamics under irreversibility and uncertainty
}

\author{
Daniel Rios-Festner ${ }^{\mathrm{a}, *}$, Gerardo Blanco ${ }^{\mathrm{a}}$, Fernando Olsina ${ }^{\mathrm{b}}$

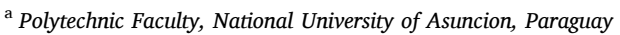 \\ ${ }^{\mathrm{b}}$ Institute of Electrical Energy, CONICET - National University of San Juan, Argentina
}

\section{A R T I C L E I N F O}

\section{Keywords:}

Capacity markets

Capacity payments

Generation investments

Real options

Supply reliability

System dynamics

\begin{abstract}
A B S T R A C T
In actual energy-only markets, the high volatility of power prices affects the expected returns of generators. When dealing with irreversibility under uncertainty, deferring decisions to commit in new power plants, waiting for better information, is therefore a rational approach. Theoretical and empirical evidence suggests that such investment pattern determines the occurrence of construction cycles, which strongly compromise supply security. In order to supplement generators' revenues, several remuneration mechanisms have been devised over past years. Along this line, this work addresses the long-run dynamics of capacity adequacy and market efficiency with both a price-based and a quantity-based capacity remuneration policy. For that purpose, a recentlydeveloped, stochastic simulation model is used as a benchmark. Hence, the optimal postponement of generation investment decisions is integrated into a long-run power market model by formulating the decision-making problem in the framework of Real Options Analysis. Results suggest that policymakers may exchange supply security (effectiveness) for energy prices to be paid by consumers (efficiency) when designing and implementing capacity remuneration mechanisms. By doing so, this article contributes to the ongoing debate regarding the design of incentive policies and efficient power markets by considering the microeconomics of investors' decision-making under irreversibility and uncertainty.
\end{abstract}

\section{Introduction}

Over the last 30 years, electricity markets worldwide have faced the process of liberalization. This term refers to the unbundling of the former vertical industry, and the introduction of competition (mainly) in the generation segment. Now, the generation expansion involves multiple self-oriented firms making individual investment decisions and seeking to maximize their own financial profits. In order to decide investments, generation companies follow price signals associated to a remuneration obtained from the Optimal Spot Price Theory (Caramanis et al., 1982). Under perfect competition, the market rewards each firm at a price set by the marginal cost of the most expensive generation unit in service, according to an economic dispatch. Under short-term demand irresponsiveness, when supply and demand cannot be cleared, the market price escalates to a rather high value (in contrast to production costs), which denotes the marginal cost of load shedding, i.e. the Value of Lost Load (VOLL). This arrangement corresponds the traditional structure of liberalized power markets, and is known as the energy-only market (Stoft, 2002).
Energy-only markets theoretically offer sufficient incentives to guarantee the financial return of investors in the long run and thereby to ensure supply security (Caramanis, 1982). Such market architecture would allow efficient investments to expand the generating capacity, in response to demand growth, with an appropriate level of reliability. Nonetheless, actual markets tend to exhibit imperfections, such as information asymmetries, herding behavior, and bounded rational expectations. In the context of high uncertainty, investors are prone to be risk-averse when deciding to invest in new power plants, thus affecting the ideal process of keeping system adequacy. This is due to the interaction between the volatility of revenue coming from the energy-only market and the formation of profitability expectations by investors. In the long term, this leads to the appearance of so-called construction cycles of generating capacity. This situation describes the long-term evolution of power systems in terms of subsequent periods of under- and over-investment in power plants. The literature provides empirical evidence on the existence of construction cycles in the electricity industry since the late 1980s (Arango and Larsen, 2011).

The volatile system behavior severely affects the security of power supply. Risk of deficient supply reliability is perceived as an

\footnotetext{
* Corresponding author.

E-mail addresses: dfestner@pol.una.py (D. Rios-Festner), gblanco@pol.una.py (G. Blanco), olsina@iee.unsj.edu.ar (F. Olsina).
} 


\begin{tabular}{|c|c|c|c|}
\hline \multicolumn{2}{|c|}{ Abbreviations } & \multirow{3}{*}{$\begin{array}{l}K_{i j}^{c u m} \\
\dot{K}_{i}\end{array}$} & \multirow{3}{*}{$\begin{array}{l}\text { Aggregated system capacity up to vintage } j \text { from } \\
\text { technology } i \text {, according to the dispatch merit order [MW] } \\
\text { Change in capacity from technology } i \text { [MW/year }]\end{array}$} \\
\hline CC & Combined-cycle generation technology & & \\
\hline CLD & Causal-loop Diagram & & \\
\hline $\mathrm{CM}$ & Capacity Market & \multirow[t]{2}{*}{$\dot{K}_{i j}^{i n}$} & Rate at which capacity enters vintage $j$ from technology $i$ \\
\hline $\mathrm{CP}$ & Capacity Payment & & [MW/year] \\
\hline $\mathrm{CT}$ & Construction Time & \multirow[t]{2}{*}{$\dot{K}_{i j}^{\text {out }}$} & Rate at which capacity abandons vintage $j$ from technology \\
\hline $\mathrm{CV}$ & Continuation Value & & $i[\mathrm{MW} /$ year $]$ \\
\hline CVaR & Conditional Value at Risk & $K_{I}^{*}$ & Desired total installed capacity [MW] \\
\hline $\mathrm{DDE}$ & Delay Differential Equation & $K_{T}$ & Total installed capacity [MW] \\
\hline DPE & $\begin{array}{l}\text { Dynamic Programming based on the Expected present } \\
\text { value }\end{array}$ & $K_{T}^{r}$ & $\begin{array}{l}\text { Stochastic realization } r \text { of expected total installed capacity } \\
\text { [MW] }\end{array}$ \\
\hline EO & Energy-only market & $i m_{i}$ & Investment multiplier for technology $i$ [adim] \\
\hline EV & Exercise Value & $i m_{i}^{\max }$ & Maximum investment multiplier for technology $i$ [adim] \\
\hline GT & Gas-turbine generation technology & $I C_{i}$ & Investment cost for technology $i[€ / \mathrm{MW}]$ \\
\hline GW & Gigawatt & $\dot{I}_{i}$ & Investment rate for technology $i$ [MW/year] \\
\hline $\begin{array}{l}\text { HC } \\
\text { HUS }\end{array}$ & $\begin{array}{l}\text { Hard-coal generation tech } \\
\text { Hourly Unitary Surplus }\end{array}$ & $\dot{I}_{i}^{r e f}$ & Reference investment rate for technology $i$ [MW/year] \\
\hline IRR & Internal Rate of Return & $L$ & Load level exceeding an annual duration $d$ [MW] \\
\hline LDC & Load Duration Curve & $L^{r}$ & Stochastic realization $r$ of load level exceeding an annual \\
\hline LOLP & Lost of Load Probability & & duration $d[\mathrm{MW}]$ \\
\hline MW & Megawatt & $\dot{L_{i}}$ & Expected change in portion of peak load covered by \\
\hline MWh & Megawatt-hour & & technology $i[\mathrm{MW} /$ year $]$ \\
\hline NPV & Net Present Value & $L_{\min }$ & Minimum demand $[\mathrm{MW}]$ \\
\hline PDC & Price Duration Curve & $L_{\max }$ & Maximum demand [MW] \\
\hline PI & Profitability Index & $M_{i}$ & Option Maturity for technology $i$ [year] \\
\hline ROA & Real Options Analysis & $\overline{M C}_{i}$ & Marginal cost of capacity from technology $i[€ / \mathrm{MWh}]$ \\
\hline RSME & Root Square Mean Error & $E M P$ & Expected market price $[€ / \mathrm{MWh}]$ \\
\hline VaR & Value at Risk & $P_{\text {avg }}$ & Average unit size system-wide [MW] \\
\hline SD & System Dynamics & $P C$ & Average system production cost $[€ / \mathrm{MWh}]$ \\
\hline VOLL & Value of Lost Load & $P I_{i}$ & Profitability index for technology $i$ [adim] \\
\hline \multirow{2}{*}{\multicolumn{2}{|c|}{ List of Symbols: Roman symbols }} & $q$ & Expected availability of generating units [adim] \\
\hline & & $r$ & Superscript to denoted realizations of stochastic variables \\
\hline & $\begin{array}{l}\text { Blading iactor ior new capacity in the capacity market } \\
{[\mathrm{MW}]}\end{array}$ & & [adim] \\
\hline$A P_{i}$ & Annual unitary profits expected by technology $i$ from the & $R M^{*}$ & $\begin{array}{l}\text { System reserve margin [adim] } \\
\text { Desired system reserve maroin [adim] }\end{array}$ \\
\hline \multirow{3}{*}{$d$} & energy-only market $[€ / \mathrm{MW} \cdot$ year $]$ & $S$ & Number of simulation time steps [adim] \\
\hline & \multirow{2}{*}{$\begin{array}{l}\text { Annual duration probability to exceed a given load level } L \\
\text { [adim] }\end{array}$} & $t$ & Dynamic time [year] \\
\hline & & $T$ & Simulation horizon [year] \\
\hline$D_{\text {def }}$ & Annual probability of deficit duration system-wide [adim] & $T_{i}$ & Lifetime for technology $i$ [year] \\
\hline$D_{i}$ & \multirow{2}{*}{$\begin{array}{l}\text { Annual probability for one MW of new capacity from } \\
\text { technology } i \text { to operate with market price over own } \\
\text { marginal costs [adim] }\end{array}$} & $T_{i}^{A}$ & Amortization period for technology $i$ [year] \\
\hline \multirow{3}{*}{$D_{i j}$} & & $T_{i}^{C}$ & Construction lead-time for technology $i$ [month] \\
\hline & $\begin{array}{l}\text { Annual probability for the capacity of vintage } j \text { from } \\
\text { technology } i \text { to operate with market price over own }\end{array}$ & $T P_{T_{i}^{A}}$ & $\begin{array}{l}\text { Expected stream of total operating profits for technology } i \\
\text { over } T_{i}^{A}[€ / \mathrm{MW}]\end{array}$ \\
\hline & marginal cost [adim] & $V_{i}^{*}$ & Optimal investment policy for technology $i[€ / \mathrm{MW}]$ \\
\hline$d t_{i}$ & Time increment between $t$ and $M$ for technology $i$ [month] & $V_{i}^{\text {cont }}$ & Continuation value for technology $i[€ / \mathrm{MW}]$ \\
\hline$€$ & Symbol of currency (Euro) & $V_{i}^{e x}$ & Exercise value for technology $i[€ / \mathrm{MW}]$ \\
\hline$g_{F P}^{i}$ & $\begin{array}{l}\text { Growth rate for the fuel price of capacity from technology } i \\
\text { [\%/year] }\end{array}$ & \multicolumn{2}{|c|}{ Greek symbols } \\
\hline$g_{K}^{r}$ & $\begin{array}{l}\text { Stochastic realization } r \text { of growth rate for the total system } \\
\text { capacity [\%/year] }\end{array}$ & $\alpha_{i}$ & $\begin{array}{l}\text { Factor to control the slope of the multiplier curve for } \\
\text { technology } i \text { [adim] }\end{array}$ \\
\hline$g_{L}$ & $\begin{array}{l}\text { Long-term growth rate for maximum and minimum } \\
\text { demand }[\% / \text { year }]\end{array}$ & $\beta_{i}$ & $\begin{array}{l}\text { Factor to define the x-axis position of the multiplier curve } \\
\text { for technology } i \text { [adim] }\end{array}$ \\
\hline$g_{m}$ & Growth rate for minimum demand [\%/year] & $\pi_{C M}$ & Capacity market clearing price $[€ / \mathrm{MW} \cdot$ year $]$ \\
\hline$g_{M}$ & Growth rate for maximum demand [\%/year] & $\pi_{E M}$ & Annual unitary revenues coming from the energy-only \\
\hline$g_{m}^{r}$ & $\begin{array}{l}\text { Stochastic realization } r \text { of growth rate for minimum } \\
\text { demand [\%/year] }\end{array}$ & $\pi_{i}$ & $\begin{array}{l}\text { Annual unitary rents expected by technology } i \text { from the } \\
\text { energy-only market }[€ / \mathrm{MW} \text {-year] }\end{array}$ \\
\hline$g_{M}^{r}$ & $\begin{array}{l}\text { Stochastic realization } r \text { of growth rate for maximum } \\
\text { demand [\%/year] }\end{array}$ & $\pi_{i}^{b i d, n e w}$ & Bid price of new capacity from technology $i$ in the capacity \\
\hline$i$ & Subscript to individualize generating technologies [adim] & & market $[€ / M W \cdot$ year $]$ \\
\hline$I C_{i}$ & Investment cost for technology $i[€ / \mathrm{MW}]$ & $\pi_{i j}^{b i d, o l d}$ & Bid price of existing capacity from vintage $j$ of technology $i$ \\
\hline j & Subscript to individualize vintages from each generating & & in the capacity market $[€ / M W \cdot$ year $]$ \\
\hline & & $\pi_{i}^{C M}$ & Annual unitary rents expected by technology $i$ from the \\
\hline$K_{\text {bid }}^{\text {new }}$ & Bid of new capacity in the capacity market [MW] & & \\
\hline
\end{tabular}


capacity market [€/MW·year]

Annual unitary rents expected by technology $i$ from capacity payments $[€ / \mathrm{MW} \cdot \mathrm{year}]$

Required revenue rate for each technology [\%/year]

$\rho$

$\phi_{i}$ Risk-free discount rate for technology $i$ [\%/year]

Symbols of the mean-reverting stochastic process

$d g \quad$ Expected change in a growth rate

$d t \quad$ Time increment

$g$ $\bar{g} \quad$ Long-term (mean) growth rate

$\eta \quad$ Speed of reversion towards the mean growth rate

$\sigma \quad$ Volatility of the growth rate

$d z \quad$ Variable following a Wiener Process

$\varepsilon \quad$ Normally distributed random variable

$N \quad$ Number of correlated, stochastic variables

$B \quad$ Matrix of $N$ correlation coefficients

$\varepsilon_{N} \quad$ Set of $N$ uniformly distributed random variables

$\theta_{N} \quad$ Set of $N$ correlated random variables unacceptable outcome since electricity is a critical input to modern economies. Therefore, several systems have envisioned the integration of capacity remuneration mechanisms in order to acknowledge the role of generators in guaranteeing supply security. The design and implementation of these mechanisms is attributed to the system administrator (government or regulator), and depend mostly on the power market itself. The literature recognizes a consensus in classifying capacity remuneration mechanisms according to two types, so-called price-based and quantity-based (Bublitz et al., 2019). Under price-based mechanisms, the administrator sets an additional revenue for generators in return for assuring supply security. The product indicating the security of supply is often referred to the firm capacity of generators. Because of that, this mechanism is usually known as capacity payment. Quantity-based mechanisms involve a quite different approach. Here, the demand is obliged to purchase (directly, or through the regulator) an explicit quantity of the product expressing supply security. In that sense, such product might adopt several forms, including the system's firm capacity, capacity credits, capacity certificates, and forward contracts, among others (Battle and Rodilla, 2010).

In recent years, capacity mechanisms have been introduced in many developed markets, e.g. Australia, the European Union, Scandinavia, the United Kingdom, and the United States, and emerging economies (e.g. some Latin American countries). Nonetheless, the cumulated experience is yet insufficient to agree on the contribution and effectiveness of the several capacity mechanisms implemented to the long-term security of supply (Schreiber, 2018). For instance, certain markets, e.g. Ireland, Italy and Poland, are currently planning to adapt their prevailing capacity mechanism. Moreover, Spain applied a new mechanism in 2016, after abolishing the investment incentive in place since 2007. The Spanish case is exemplary since the success of the former capacity mechanism was severely affected by an economic crisis and a demand growth lower than expected (Bublitz et al., 2019).

In general, foreseeing the long-term dynamics of liberalized power markets is extremely difficult. Thus, generators, governments and regulators need to rely on mathematical models to gain insight on the longrun market behavior. In this vein, simulation models are able to reproduce the rationale, incentives and limitations behind the decision-making of competing generators, including aspects such as bounded rationality, learning abilities, imperfect foresight, etc. (Ventosa et al., 2005). A suitable approach to formulate simulation models of complex systems, $e$. g. competitive generation systems, is System Dynamics (SD) (Sterman, 2000). First, SD concentrates on outlining the logical interrelationships among several components, thus characterizing the system under study through a macroscopic description of the feedback structure. Then, the evolving state of the system is expressed in terms of a set of non-linear delay differential equations. Finally, the system behavior in the long term raises from the numerical resolution of such set of equations.

The literature includes a broad body of articles that employ SD to assess the expansion of competitive generation systems in the long run (Leopold, 2015; Ahmad et al., 2016; Rios et al., 2016). By following the traditional approach, the majority of works has studied the energy-only market (Bunn and Larsen, 1992; Bunn and Larsen, 1994; Kadoya et al., 2005; Eager et al., 2010; Pereira and Saraiva, 2011; Osorio and van
Ackere, 2016; Movahednasab et al., 2017). In agreement with the observed global trend, several articles have as well assessed the electricity market development with the adoption capacity mechanisms. Most of these works have analyzed the implementation of price-based mechanisms, e.g. capacity payments (Ford, 1999; Assili et al., 2008; Hasani-Marzooni and Hosseini, 2013; Pereira and Saraiva, 2013; Ibanez-Lopez et al., 2017). In recent years, research focus has been mainly on evaluating quantity-based mechanisms, comprising a capacity market and a strategic reserve mechanism (Hary et al., 2016); a forward market (Alvarez-Uribe et al., 2018); and a capacity certificate (Heidarizadeh and Ahmadian, 2019). Both price-based and quantity-based mechanisms have been assesed by de Vries and Heijnen (2008) and Hasani-Marzooni and Hosseini (2011a). Furthermore, some of these articles explicitly introduce metrics for assessing the market development more rigorously (Assili et al., 2008; de Vries and Heijnen, 2008; Hary et al., 2016). These metrics often contrasts the effectiveness against the efficiency of the capacity incentive. On one hand, effectiveness can refer to the degree of supply security, while, on the other hand, efficiency can be related to energy costs for consumers.

Beyond the remuneration design, all of these articles have described the addition of new power plant projects by assuming risk-neutral investors, e.g. by computing the classical expected Net Present Value (NPV) of new investments. Fewer works have characterized the risk-aversion associated to generators' decision-making, as evidenced by the experienced of actual power markets. These efforts mainly deal with an energy-only market design, and include the application of a riskadjusted Internal Rate of Return (IRR) (Olsina et al., 2006; Olsina and Garces, 2008; Sanchez et al., 2008); and the Value at Risk (VaR) approach (Eager et al., 2012). Even so, recent articles have employed SD to analyze the impact of capacity mechanisms (e.g. a capacity market and a strategic reserve mechanism) on the mitigation of construction cycles, by assuming risk-averse investors. On one hand (Petitet et al., 2017), introduces a utility function where the coefficient of risk-aversion controls the responsiveness of investors to the expected NPV of new power plant projects. On the other hand (Abani et al., 2018), adjusts the expected profitability of new investments by applying the Conditional Value at Risk (CVaR) approach.

\subsection{Contribution}

In liberalized power markets, the risk-aversion of investors originates mainly due to characteristics of power plant projects, e.g. capitalintensive, one-step outlays, long payback times, and irreversibility (Dixit and Pindyck, 1994). Furthermore, decisions have to be made within a dynamic market setting, marked by the interaction of multiple, self-oriented generators and the development of uncertain variables. Keeping that in mind, risk-aversion suggests that investors would delay construction of new generating units until the expected profits were certain and large enough. This possibility derives from considering a major attribute of power plant investments, known as the postponement (or deferral) option. Formally, this concept refers to the preference of investors to withhold the addition on new generating units when facing major uncertainties upon the electricity market development (Blanco 
and Olsina, 2011). The availability of the deferral option embedded in most generation project provides with an alternative description to the occurrence of construction cycles, in terms of the decision-making of irreversible investments under uncertainty. The observed behavior of postponing decisions to commit into irreversible investments under uncertainty was first acknowledged in a SD long-term electricity market model by delaying the investment signal in a fixed amount (Olsina, 2005; Olsina et al., 2006). Nonetheless, this overly simplistic approach is unable to capture the microeconomics behind the dynamic interactions among strategic flexibility, investment irreversibility and uncertainty.

In order to cope with this aspect suitably, modern investment valuation tools should be applied. One of such approaches involves Real Options Analysis (ROA), which offers a well-founded framework that allows seizing the availability of options, ${ }^{1}$ thus making strategic investment decisions (Brosch, 2001). The idea behind ROA is to assign with a value to all options inherent to an investment project, in addition to calculating its NPV. By definition, the option value is always positive. Because of that, its computation increases the regular project value and provides with strategic flexibility to the decision-making. The value of complex real options is obtained by option pricing methods based on stochastic simulation combined with approximate dynamic programing (Longstaff and Schwartz, 2001; Blanco and Olsina, 2011). This simulation-based option valuation approach is commonly referred as Least-square Monte Carlo (LSM). Ultimately, by applying ROA, market uncertainties affecting project returns are offset thanks to the definition of a lower limit to potential losses, ${ }^{2}$ while the opportunity for capturing large profits remains open.

A recent work addresses the long-run dynamics of generation capacity adequacy in energy-only markets under consideration of the flexibility value of deferring decision to build new power plants (Rios et al., 2019). For that purpose, the market dynamics are modeled with $\mathrm{SD}$, while the option value of new projects is computed by means of ROA and stochastic dynamic programming. This work seeks to take advantage of the proposed modeling approach in order to assess the long-term evolution of power markets when investors consider different capacity incentives under irreversibility and uncertainty. By adopting System Dynamics modeling approach, the decision-making of a number of investors can be described in an aggregated fashion. Here, such aggregated behavior is classified according to three generating technologies. This mathematical methodology is adopted because it allows to easily model informational and physical feedbacks, nonlinearities and stock and flows structures of dynamical systems, e.g. competitive power markets. ${ }^{3}$

The capacity mechanisms discussed in this article imply both, a price-based capacity payment and a quantity-based capacity market. The first mechanism is inspired by the dynamic remuneration introduced in England and Wales between 1990 and 2001. Under such scheme, investors received a price uplift given by the probability of capacity shortfall, i.e. the Loss of Load Probability (LOLP), times the energy scarcity price, given by the VOLL. The second incentive is comparable to the capacity mechanism prevailing in France and Great Britain (RTE, 2014; DECC, 2014). It involves the definition of a capacity obligation in advance, which equals a peak load forecast plus a target reserve margin. Generators offer existing and new capacity seeking to

\footnotetext{
1 Alongside the postponement, these options might also include expansion, abandonment, switch-business, switch-input, closing and reopening (Copeland and Antikarov, 2003).

2 These losses refer mainly to the price paid to obtain the right to exercise the option.

${ }^{3}$ It is important to point out that, under perfect competition, valuation of postponement option does not depend on investment decisions made by competing firms. Indeed, the deferral option can correctly be valued by myopically assuming the firm is in isolation (as it was a monopolist) and exposed only to competitive fuel and power prices. This important result has been demonstrated in Dixit and Pindyck (1994), Chapter 8.
}

reach that obligation. Hence, the capacity market clearing price sets the additional remuneration of investors.

In both cases, the capacity mechanism will increase the revenue obtained in the energy-only market. New power capacity additions will then be decided based on the application of ROA, by deeming the possibility to defer the investment decision while key uncertainties are resolved. By doing so, this article offers an innovative assessment of power capacity incentives by modeling the long-run investment dynamics under irreversibility and uncertainty. It is assumed that a lower revenue volatility, thanks to the introduction of capacity mechanisms, would allow timely capacity additions, thereby enabling a steadier evolution of the reserve margin in the long term. Thus, this work contributes in shedding light on the ongoing discussion about the performance of such remuneration mechanisms based on long-term market dynamics.

We organize the reminder of this article as follows: Section 2 describes the proposed market model; Section 3 discusses obtained results; and finally Section 4 provides the concluding remarks with emphasis on the policy implications.

\section{Modeling power market dynamics with capacity mechanisms}

\subsection{Model overview}

The feedback structure driving the long-run power market evolution with the remuneration alternatives discussed in this work is depicted in the Causal-loop Diagram $\left(\mathrm{CLD}^{4}\right)$ of Fig. 1. This diagram is constructed upon previous contributions included in Olsina et al. (2006) and Rios et al. (2019), which describe the dynamic development of electricity markets from the point of view of investor's decision-making. The information flow throughout the CLD is described as follows. Investors perceive an instant energy price signal, according to the capacity reserve and fuel costs (loop B1). Simultaneously, they form expectations upon future energy prices based on uncertainties driving the development of the same parameters (loop B2). The capacity reserve also influences the

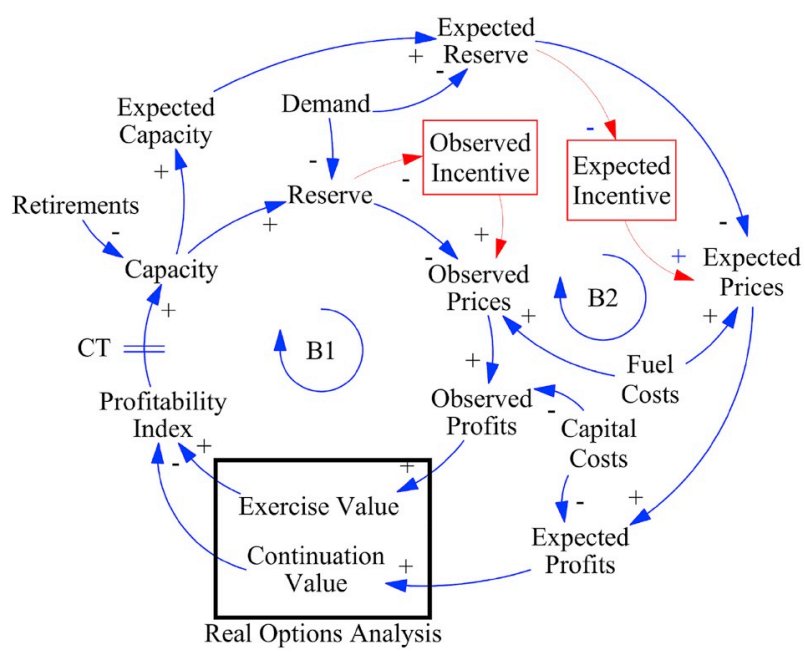

Fig. 1. CLD describing the dynamics of generation capacity additions in a power market with capacity incentives.

\footnotetext{
${ }^{4}$ A CLD is an analysis tool from SD modeling that allows depicting the overall feedback structure of complex systems. A CLD includes variables linked by arrows representing causal influence. Each causal link is assigned a polarity (either positive ( ) or negative ( )), indicating how the dependent variable changes when so does the independent variable.
} 
existence of capacity incentives. On one hand, if the reserve margin decreases, more units would be operating over longer periods in order to meet demand, probably affecting maintenance schedules, and thus increasing a capacity payment based on the expected price approach. On the other hand, a decreasing reserve would also mean the installed capacity falling behind its target, set in the context of a capacity market and an expected, long-term demand growth. Thus, more expensive generation units would clear the capacity market, which would as well upturn the price signal and the remuneration coming from such capacity market.

The price signal of the energy-only market, plus remunerations, would be compared against capital costs in order to determine the profitability on new power plants. By assuming the risk-aversion of investors, the decision-making would also consider the irreversibility under uncertainty and the strategic flexibility to postpone new investments. Hence, by applying ROA concepts, new power plants would be decided based on the computation of two values, so-called the Exercise Value (EV) and the Continuation Value (CV). On one hand, the EV would denote an observed profitability, in terms of the typical NPV of immediately undertaking new power plants. On the other hand, the CV would give an expected profitability, i.e. a discounted NPV, if the decision were to postpone investments and exercise them after some time. Such time is known as the Option Maturity, and specifies the future moment when a decision must be made about the project (exercise or not), if deferred.

A Profitability Index (PI), given the ratio between the EV and the CV, would indicate the amount of new investments to be added into the system at each simulation step. New power plants would come to operation after a given Construction Time (CT). Only then, a new level of installed capacity would be defined by the sum of existing capacity and new investments, minus the decommissioning of old power plants. This capacity, in comparison to the observed demand, would finally set a new level of capacity reserve, and therefore, a new prevailing level of energy prices. Considering the logic behind the CLD of Fig. 1, a set of nonlinear differential equations should be formulated in order to reproduce the power market dynamics. The next subsections provide details on this mathematical model.

\subsection{Underlying power market model}

The impact of remuneration mechanisms on power market dynamics is analyzed by taking advantage of a structural power market model. Such model provides a solid mathematical background that allows describing the long-term dynamics of electricity markets. For the sake of brevity, this article only offers an overview about its main features. For further details, the reader is referred to Olsina et al. (2006) and Rios et al. (2019).

\subsubsection{Supply side model}

A test generation system is considered, including only three thermal technologies: base (coal-fired plants - HC), middle (gas-fired combined cycles - CC), and peak (gas turbines-GT). Based on initial conditions of electricity demand, fixed and variable generation costs, the optimal technology mix at the beginning of simulations comprises $72.31 \%$ of HC;
$14.43 \%$ of CC; and $12.26 \%$ of GT; with an initial system capacity equal to $16.46 \mathrm{GW}$. Such optimal mix is associated to the economically optimal level of supply reliability, which derives an optimal reserve margin equal to $9.75 \%$ for this test system. ${ }^{5}$ The optimal reliability level for this system implies an initial capacity shortfall probability (LOLP) of 0.0052 . The initial mix is attained by computing the screening curves ${ }^{6}$ for the three technologies under study.

The age progression of generating units is simulated endogenously by implementing a capacity aging chain. ${ }^{7}$ Thus, the generating capacity is classified for each technology in five vintages. In addition, it is supposed that any unit of capacity will reside in the system over its entire lifetime. Based on operation premises of base, middle and peak technologies, distinct values equal to 40,30 and 20 years denote lifetimes of HC, CC and GT, respectively.

When simulations start, capacity additions are endogenously decided based on prevailing profitability expectations that prospectively offer each generating technology. At each time step $t$, the net change in capacity from technology $i, \dot{K}_{i} t$ [MW/year], is formulated as:

$\dot{K}_{i} t \quad \dot{K}_{i 1}^{\text {in }} t \quad \dot{K}_{i 5}^{\text {out }} t$

where $\dot{K}_{i 1}^{\text {in }} t$ is the completion rate of new units, while $\dot{K}_{i 5}^{\text {out }} t$ is the decommission rate of old units. Since lifespan of generating units are assumed constant, $\dot{K}_{i 5}^{\text {out }} t$ is the completion rate at time $t \quad T_{i}$, that is $\dot{K}_{i 5}^{\text {out }} t \quad \dot{K}_{i 1}^{\text {in }} t \quad T_{i}$ with $T_{i}$ being the lifetime of technology $i$.

The completion rate $\dot{K}_{i 1}^{i n} t$ denotes the investment rate that prevailed at time $t \quad T_{i}^{C}$, with $T_{i}^{C}$ being the construction time for technology $i$. By considering distinct premises for the completion of units from each generating technology, typical values equal to 36,18 and 9 months are assigned to the mean construction time of HC, CC, and GT power plants, respectively. The investment rate for technology $i$ at time $t T_{i}^{C}$, $\dot{I}_{i} t \quad T_{i}^{C} \quad$ [MW/year], is thus calculated by:

$\dot{K}_{i 1}^{\text {in }} t \quad \dot{I}_{i} t \quad T_{i}^{C} \quad i m_{i} P I_{i} t \quad T_{i}^{C} \quad * I_{i}^{r e f} t \quad T_{i}^{C}$

At time $t \quad T_{i}^{C}$, the investment multiplier for technology $i, i m_{i} P I_{i} t$ $T_{i}^{C}$, is subject to the profitability index, $P I_{i} t \quad T_{i}^{C}$, introduced by the CLD of Fig. 1. Hence, logistic functions are defined to reproduce the effect of the PI on the investment rate for each technology. Analytically, these functions are obtained at time $t$ by:

$i m_{i} t \quad \frac{i m_{i}^{\max }}{1 \quad e^{\alpha_{i}^{*} P_{i} t} \beta_{i}}$

In Eq. (3), for each technology $i, i m_{i}^{\max }$ denotes the level of saturation of the logistic functions; $\alpha_{i}$ controls the slope, and $\beta_{i}$ defines the position of the sigmoid with respect to the $\mathrm{x}$-axis. The saturation level seeks to represent the cautious behavior of investors, even when facing high profitability conditions, as they known the danger of an investment overreaction to favorable short-term market context. Distinct values are

\footnotetext{
5 The optimal level of supply reliability is determined when the marginal cost of serving an additional MW of peak load equals the marginal cost of installing and operating an additional MW of peak capacity.

6 Screening curves depict the total unit operating costs (fixed plus variable) as a function of the capacity factor. On one hand, fixed costs are associated to investment costs, amortization times, and revenue discount rates. On the other hand, variable costs are associated to the marginal generation cost of each technology. By assuming solely thermal technologies, the marginal cost depends mainly on the fuel price and the heat rate of each generation unit. The applied method is explained by Olsina et al. (2006) and is referred to Stoft (2002).

7 Aging chains differentiate a production capacity in terms of productivity. In this case, such productivity is associated to the thermal efficiency of generating units.
} 
assumed for the parameters of the logistic functions of each generation technology, since the risks involved are different for the several technologies (minimum economic unit size and, investments costs). Nonetheless, it is worth to mention that the tipping point for each function will occur when the PI is one. At that point, the investment rate would adopt a reference value, $I_{i}^{\text {ref }}$ [MW/year], i.e. an investment rate derived from zero profitability expectations. This variable is computed at time $t$ by:

$\dot{I}^{\text {ref }} t \quad \dot{K}_{i 5}^{\text {out }} t \quad \dot{L}_{i} t$

Here, $\dot{K}_{i 5}^{\text {out }} t$ is the decommission rate of technology $i$, while $\dot{L}_{i} t$ is the completion rate required for such technology to match the expected growth of peak load while the optimal technology mix is preserved. The mathematical framework behind the computation of this latter variable can be found in Olsina et al. (2006). It is worth to mention that model parameters are provided in extent in Section 3.

\subsubsection{Demand side model}

Given the long-term nature of the study, power demand is represented in terms of a Load Duration Curve (LDC). A LDC results from sorting the chronological load analyzed over a certain time (e.g. 1 year), from maximum to minimum. Without losing generality, and seeking to maintain the model simple, it is assumed that LDC would adopt a linear pattern over the entire simulation time. The initial condition for the LDC is therefore expressed by:

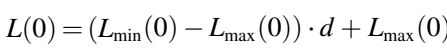

In Eq. (5), $L 0$ is the amount of load that would exceed a cumulated duration $d$ over the analyzed period (e.g. 1 year), given the maximum and minimum demand, $L_{\max } 0$ and $L_{\min } 0$, respectively. By ignoring plausible structural variations, the LDC would keep its linear shape in the long run. Hence, by knowing the initial values of peak and minimum demand, the LDC at time $t$ is formulated as:

$L t \quad L_{\min } 0 \cdot e^{g_{m} \cdot t} \quad L_{\max } 0 \cdot e^{g_{M} \cdot t} \cdot d \quad L_{\max } 0 \cdot e^{g_{M} \cdot t}$

where $g_{m}$ and $g_{M}$ represent growth rates for peak and minimum demand, respectively. Typical values assigned to these parameters are fully included in Section 3. In addition, it is worth to note that power demand is assumed inelastic in the short run with respect to sudden changes of the energy price. Notwithstanding, if electricity prices escalate above the curtailment cost, it is supposed that consumers will decline to buy any additional energy. Here, such cost is denoted by the VOLL, which adopts an illustrative value of $1000 € /$ MWh.

\subsubsection{Uncertainty model}

The evolution of key variables of power markets is uncertain by nature. For instance, despite being able to observe the long-term trend of LDC parameters, generators might equally anticipate random fluctuations of growth rates around their deterministic value. These fluctuations depend upon external factors, such as changes of weather, jointly with sudden variations of the economic activity.

Modeling uncertainties is critical for the underlying power market model because both the observed (deterministic) and the expected (stochastic) values of key variables are employed to compute the EV and the CV at each simulation step. Rios et al. (2019) include a literature review on the evidence supporting the adoption of the mean-reverting stochastic process for describing the expected growth of commodities, e.g. fuel prices, and power demand. Furthermore, Olsina (2005) estimates parameters of mean-reverting processes from actual data of consumption growth rates corresponding to three different electricity systems (Argentina, Germany, and Spain). These models allow simulating paths that replicate well-enough the stochastic patterns of demand growth rates evidenced by the historical datasets. Therefore, this stochastic process is adopted to reproduce stochastic paths of uncertain demand growth in a plausible and realistic way.

Formally, the simplest mean-reverting process, known as the arithmetic Ornstein-Uhlenbeck stochastic process (Gillespie, 1996), is expressed by:

$d g \quad \eta \cdot \bar{g} \quad g \cdot d t \quad \sigma \cdot d z$

In Eq. (7), the expected change in the growth rate $d g$, after time step $d t$, depends upon the deviation of the growth rate $g$ from its trend value $\bar{g}$, times the speed of reversion towards the trend, $\eta$. It is also contingent upon the product of the volatility parameter $\sigma$, and the variable reproducing a Brownian Motion, $d z$. An infinitesimal increment of this variable is assumed to be denoted in continuous time by:

$d z \quad \varepsilon \cdot \sqrt{ } d t$

where $\varepsilon$ represents a stochastic realization of a random variable sampled over the standardized normal distribution, i.e. $\varepsilon \quad N 0,1$.

The model incorporates a description of the correlation between growth rates of power demand and capacity. This seeks to characterize the uncertainty driving the market evolution in a more realistic way. In that context, the set of $N$ correlated variables $\theta_{N}$, is required for replacing the set of $N$ uniformly-random variables $\varepsilon_{N}$. For this purpose, the Cholesky decomposition is applied to the correlation matrix $B$, of dimension equal to $N$. In this case, $N$ 2, given 2 correlated variables (growth rates of demand and capacity). By considering the decomposed matrix $B$, and the set of random variables $\varepsilon_{N}$, the set of correlated variables $N$, is derived by following the method presented by Huang (2009).

Given Eq. (7), multiple stochastic realizations of the correlated growth rates can be sampled by applying Monte Carlo techniques. Then, a stochastic realization $r$, for both the expected demand and generation capacity at a certain future time $M \quad t d t$, is represented by:

$L^{r} M \quad L_{\min } t \cdot e^{g_{m}^{r} \cdot d t} \quad L_{\max } t \cdot e^{g_{M}^{r} \cdot d t} \cdot d \quad L_{\max } t \cdot e^{g_{M}^{r} \cdot d t}$

$K_{T}^{r} M \quad K_{T} t \cdot e^{g_{K}^{r} \cdot d t}$

In Eq. (9), $L^{r} M$ is a realization for the load level exceeding a cumulated duration $d$ at time $M$, given the maximum and minimum load observed at time $t, L_{\max } t$ and $L_{\min } t$, respectively, and the corresponding stochastic growth rates, $g_{m}^{r}$ and $g_{M}^{r}$. Analogously, in Eq. (10), $K_{T}^{r} M$ is a path for the future system capacity at time $M$, based on a realization of the correlated growth rate, $g_{K}^{r}$. It is worth to mention that $K_{T} t$ is the total system capacity at time $t$, and denotes the state variable resulting from the dynamic market model.

\subsubsection{Decision-making model}

At any time $t$, an ideal investment strategy for each technology can be derived by comparing the value of immediately undertaking new power plants, i.e. the $\mathrm{EV}$, with the value of projects if they can be delayed for reassessment after some time, i.e. the CV. Such future time, known as the Option Maturity, denotes the deadline when a decision must be made (to exercise or not). Thus, the EV is related to current market conditions and the investment signal observed by investors at each simulation step. Conversely, the CV is linked to investors' unclear expectations upon future market conditions. Such expectations are expressed by a stochastic sample of investment signals at the Option Maturity. In each case, the investment signal depends upon the aggregated supply curve and the load duration curve, jointly with capacity mechanisms. Details on investment signal definition are included in the next section.

In order to apply this concept, the underlying market model adopts a ROA approach, the so-called the backward Dynamic Programming based on Expected present value (DPE) (Blanco et al., 2012). This method is built upon stochastic dynamic programming and allows developing an optimization process appropriate for deriving instantly both the $\mathrm{CV}$ and the EV for each generation technology.

By implementing this technique, the decision rule for technology $i$ at the Option Maturity $M_{i} \quad t \quad d t_{i}$ is expressed by: 
Exercise, if $\quad E\left[T P_{T_{i}^{A}} M_{i}\right]>I C_{i} M_{i}$

Do not exercise, if $\quad E\left[T P_{T_{i}^{A}} M_{i}\right] \quad I C_{i} M_{i}$

The set of conditions can be rearranged in order to formulate the value of the postponement option for technology $i$ at time $M_{i}, V_{i}^{*} M_{i}$ [€/MW], as:

$V_{i}^{*} M_{i} \quad \max \left[E\left[T P_{T_{i}^{A}} M_{i}\right] \quad I C_{i} M_{i} ; 0\right]$

Here, $T P_{T_{i}^{A}} M_{i}$ is the expected present value of the stream of entire operating profits to be made over the amortization time $T_{i}^{A}$ by a new MW of technology $i$ coming online at $M_{i}$. In addition, $I C_{i} M_{i}$ is the necessary capital outlay for such investment. Now, in order to quantify the deferral option at $t$, the value given by Eq. (11) should be discounted. If a discrete period $d t_{i}$ separates the Option Maturity for each technology, the CV of the postponement option for technology $i$ at time $t, V_{i}^{\text {cont }} t[€ / \mathrm{MW}]$, is denoted by:

$V_{i}^{\text {cont }} t \quad \frac{V_{i}^{*} M_{i}}{1 \phi_{i}{ }^{d t_{i}}}$

where $\phi_{i}$ symbolizes the risk-adjusted discount rate, and $d t_{i}$ represents the time step until the Option Maturity for technology $i$. By following the same logic, the NPV of a new MW, is used to derive the EV of the deferral option for technology $i$ at time $t, V_{i}^{e x} t$ [€/MW]. Mathematically, this value is formulated as:

$V_{i}^{e x} t \quad T P_{T_{i}^{A}} t \quad I C_{i} t$

In Eq. (13), $T P_{T_{i}^{A}} t$ is the present value of total operating profits for a new generation unit from technology $i$ being completed at time $t$; while $I C_{i} t$ symbolizes the required investment costs. A profitability index, $P I_{i} t$, for power plant projects from technology $i$ at time $t$ is defined as the ratio between the $\mathrm{EV}, V_{i}^{\text {ex }} t$, by the $\mathrm{CV}, V_{i}^{\text {cont }} t$ :

$P I_{i} t \quad \frac{V_{i}^{e x} t}{V_{i}^{\text {cont }} t}$

Based on this definition, four investment strategies can be determined from the Exercise-Continuation Value plane (Fig. 2). If the PI were greater than one, the $\mathrm{EV}$ would exceed the $\mathrm{CV}$, and thus the optimal strategy would be to Invest Now (First Strategy). However, if the PI fell between zero and one, the CV would exceed the EV, and thus investors should probably reconsider to invest later (Second Strategy). When the $\mathrm{PI}$ is smaller than zero, it is intuitive to assume that any project appraisal should be much more pessimistic. Now, if the PI were located between minus one and zero, generators are likely to defer new projects; waiting for market uncertainties to be (at least partially) unfolded (Third Strategy). Moreover, if the PI were smaller than minus one, there would

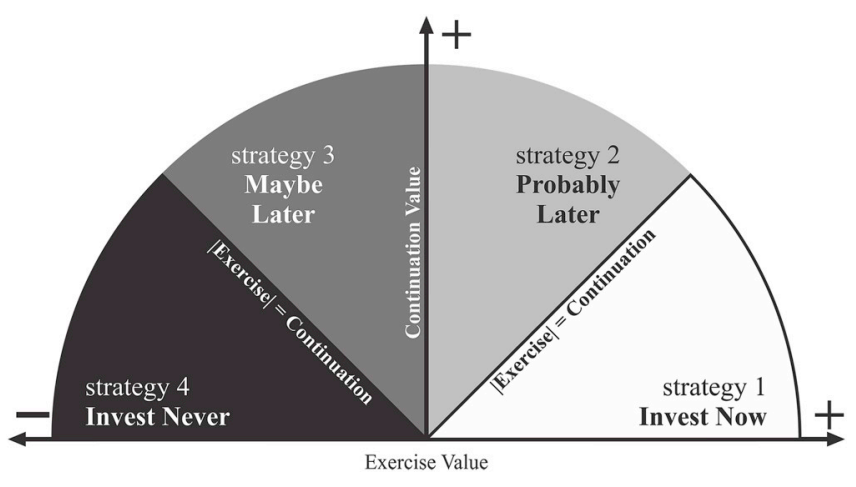

Fig. 2. Optimal decision regions in the EV-CV plane. be almost no investment incentives (Fourth Strategy). Finally, the profitability index is used to attain the aggregate investment rate for each technology, as expressed by Eq. (3). Information about model parameters (e.g. capital costs, maturity steps, discount rates) are fully included in Section 3.

\subsection{Generator remuneration model}

Operating profits introduced by Eq. (11) and Eq. (13) initially refer to an energy-only market. However, when discussing markets with capacity mechanisms, an additional source of remuneration should be taken into account. The modeling of three types of remuneration (based on an energy-only market, a capacity payment and a capacity market, respectively) is presented in this subsection.

The investment decision-making model depends upon long-term annuity equivalents (i.e. one-year equivalents) of generation profits. Because of that, the capacity revenues will denote the expected additional profit that each generator would perceive in one year thanks to capacity mechanisms. This also intends to facilitate the dimensional consistency of these revenues with the primary revenues coming from the energy-only-market. The addition of both sources of revenues will allow to obtain the total, long-run profit to be perceived by generators over the simulation time, which will be critical for the decision-making of new power plants under the two case studies of capacity mechanisms.

\subsubsection{Remuneration from an energy-only market}

Under competition, the long-term behavior of electricity prices in the spot market guide the decision-making on new power plants. In this work, the Price Duration Curve (PDC) is assumed to offer an equivalent of the distribution of spot prices over the long term (e.g. 1 year). As elaborated by Olsina et al. (2006) and Rios et al. (2019), a PDC can be derived from the aggregated supply curve ${ }^{8}$ and the LDC. In order to characterize the annual distribution of spot prices, a PDC yields (in the $\mathrm{x}$-axis) the annual probability for a capacity unit to operate with the market price over its own marginal cost of generation (in the y-axis). As mentioned in Section 2.2.1, here the system capacity is classified by age in vintages. Therefore, the set of duration probabilities for each vintage, $D_{i j}$, is computed by:

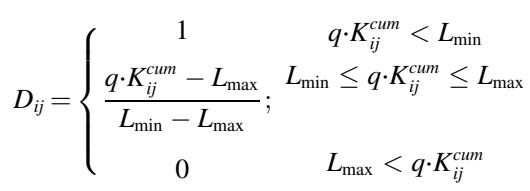

In Eq. (15), $L_{\min }$ and $L_{\max }$ characterize the LDC; while $K_{i j}^{c u m}$ denotes the amount of capacity up to vintage $j$ from technology $i$, sorted by the dispatch merit order. In addition, $q$ accounts for the expected availability of generating units. This value is attained by adopting reliability models inspired by Olsina et al. (2006). For simulations, this value is obtained according to the initial conditions of peak demand, installed capacity and expected deficit duration, and thereafter remains constant over the entire simulation period.

Since the modeling of transmission constraints is beyond the scope of this work, it is assumed that the capacity in each vintage will be dispatched any time the spot price exceeds its marginal cost of generation. Therefore, the annual revenue that $1 \mathrm{MW}$ of new capacity from technology $i$ would make, $\pi_{i}$ [€/MW.year], equals the area under the $P D C$, limited by the yearly probability of the spot price to surpass its marginal cost of production, $D_{i}$. With the total number of hours in 1 year being 8760, this can be formulated as:

\footnotetext{
${ }^{8}$ The system supply curve is referred to the aggregation of capacity units sorted according to increasing marginal cost of generation, i.e. the dispatch merit order.
} 
$\pi_{i} \quad 8760 \cdot \int_{0}^{D_{i}} P D C \cdot d D$

In accordance with Eq. (16), an investor in technology $i$ would expect that $1 \mathrm{MW}$ of new capacity made an annual profit, $A P_{i}[€ / \mathrm{MW} \cdot y e a r]$, equal to the enclosed area between the $P D C$ and its expected marginal generation cost, ${ }^{9} \overline{M C}_{i}[€ / \mathrm{MWh}]$ :

$A P_{i} \quad 8760 \cdot \int_{0}^{D_{i}} P D C \quad \overline{M C}_{i} \cdot d D$

By supposing that the annual profit obtained with Eq. (17) will remain constant over the amortization time $\bar{T}_{i}^{A}$, the present value of the expected stream of total profits to be made by the new MW from technology $i, T P_{\bar{T}_{i}^{A}} t \quad[€ / \mathrm{MW}]$, can be expressed as:

$T P_{\bar{T}_{i}^{A}} \quad A P_{i} \cdot 1 \quad \rho \bar{T}_{i}^{C} \cdot \frac{1}{\rho} \cdot\left[\begin{array}{llll}1 & 1 & \rho & \bar{T}_{i}^{A}\end{array}\right]$

Here, $\rho$ symbolizes a required return rate at which the expected stream of profits must be discounted. In addition, $\bar{T}_{i}^{C}$ is an average construction time for technology $i$, implying that investors will account for a delay between the decision-making and the actual coming to operation when estimating the benefits of new generation units.

It is worth to recognize that, in an energy only market, Eq. (18) will determine the entire operating profit to be collected by investors. Thus, at each time, the observed PDC will determine the EV, while stochastics expectations upon the PDC at the Option Maturity will determine the CV of new power plants for each technology. Despite its simplicity, the approximation given by Eq. (18) can also be explained as an efficient energy forward contract auction (Moreno et al., 2010). Finally, as noted in preceding Sections, parameters describing the proposed model are showed in Section 3.

\subsubsection{Remuneration from capacity payments}

This work adopts an approach to model capacity payments inspired by the dynamic capacity mechanism that prevailed in the former pool of England and Wales over the ' 90 s, before entering into effect the New Energy Trading Agreement (NETA) in 2001 (Chuang and Wu, 2000; Allan and Navarro Sanchez, 2004). Based on this capacity payment approach, the additional revenue that $1 \mathrm{MW}$ from technology $i$ would expect to make over 1 year, $\pi_{i}^{C P} t \quad\left[€ / \mathrm{MW} \cdot\right.$ year], can be estimated by ${ }^{10}$ :

$\pi_{i}^{C P} t \quad E L O L P t \cdot V O L L \cdot 8760 \pi_{i} t$

where ELOLP $t$ refers to the long-term expectation upon deficit probability, and $\pi_{i} t$ is the annual unitary revenue that the same $1 \mathrm{MW}$ from technology $i$ would make in the energy market, as defined by Eq. (16).

\footnotetext{
9 According to the economics of power generation, the marginal cost is associated to the variable costs of power plants. By assuming linear variable costs, the marginal cost of the conventional units under study is given by the ratio between the fuel price and its heat rate. For further details, the reader is referred to Stoft (2002).

${ }^{10}$ Under the pricing rules of the former British pool, bidding generators were paid in each hourly time interval $t$ the expected energy price $\mathrm{E} \lambda_{t}$. Future system states were assembled into two mutually exclusive sets: states without power deficit, with cumulative probability $\left(1-L O L P_{t}\right)$ and prevailing system marginal price $S M P_{t}$, and capacity shortfall (complementary) states with occurrence probability $L O L P_{t}$ and prices set at VOLL. The expected pool price that gets an available generator at time $t$ is therefore given by (Olsina et al., 2014): E $\lambda_{t} \quad 1 \quad L O L P_{t} S M P_{t} \quad L O L P_{t} \cdot V O L L$. By rearranging, the well-known pricing formulaE $\lambda_{t} \quad S M P_{t} \quad L O L P_{t} V O L L \quad S M P_{t}$ is obtained. The first term of this equation, i.e. the system marginal price, was paid only to accepted (dispatched) generators. The second term represented the dynamic hourly capacity payment to all bidding (available) generators.
}

Within an electricity market with capacity payments, an investor might then accrue a yearly net profit equal to the sum of Eq. (17) and Eq. (19). This addition should be used in Eq. (18) in order to compute the full stream of operating profits to be expected over the amortization time of each technology. Over the simulation time, both observed and expected capacity payments are critical for the decision-making model based on Real Options. Therefore, the capacity payment being observed by investors will be contingent upon the current state of the ELOLP $t$ and the $\pi_{i} t$. Analogously, expectations upon capacity payments at the Option Maturity will depend upon the future states of the ELOLP $t$ and the $\pi_{i} t$, according to the uncertain expectations upon demand and capacity growth being formed at each time.

In Eq. (19), the ELOLP $t$ is associated to the expected power deficit duration at time $t$. Here, this value defines the probability of capacity shortfall in the long term. In order to derive this parameter as a function of the reserve margin, a simple probabilistic reliability model is adopted (Olsina et al., 2006). The model involves a simple generation model plus a load model, aiming at characterizing the uncertainty upon unit availability and load forecasting. Due to space restrictions, the model is not included in this paper. Nonetheless, it is worth to note that the expected deficit duration at time $t, E D_{\text {def }} t$, and so the $E L O L P t$, can be generally expressed as:

$$
\text { ELOLP } t \quad E D_{\text {def }} t \quad f R M t, P_{\text {avg }} t, L_{\max } t
$$

Here, $R M t$ is the system reserve margin; $P_{\text {avg }} t$ denotes the average unit size in the system; and $L_{\max } t$ represents the peak load expected available capacity. The function relating the system reserve margin with the expected deficit duration is shown in Fig. 3. For further details, the extended model and assumptions are included in Olsina et al. (2006).

\subsubsection{Remuneration from a capacity market}

In this article, a capacity market model defining a long-run clearing price is adopted. Hary et al. (2016) offer an example of the application of this method, which can be seen as a long-term capacity auction mechanism. A long-term equivalent to a capacity market can be built analogously to an energy-only market. First, a supply curve would result from sorting cumulated bids of new and existing generation capacity from lower to higher. Bids of existing capacity can be given by the state variables of the generation test system, i.e. the available capacity residing instantly at each vintage from each technology. Likewise, the amount of new available capacity from technology $i$ to be bid at any time, $K_{i}^{\text {bid,new }} t$ [MW], can be proportional to its installed capacity, $K_{i} t$

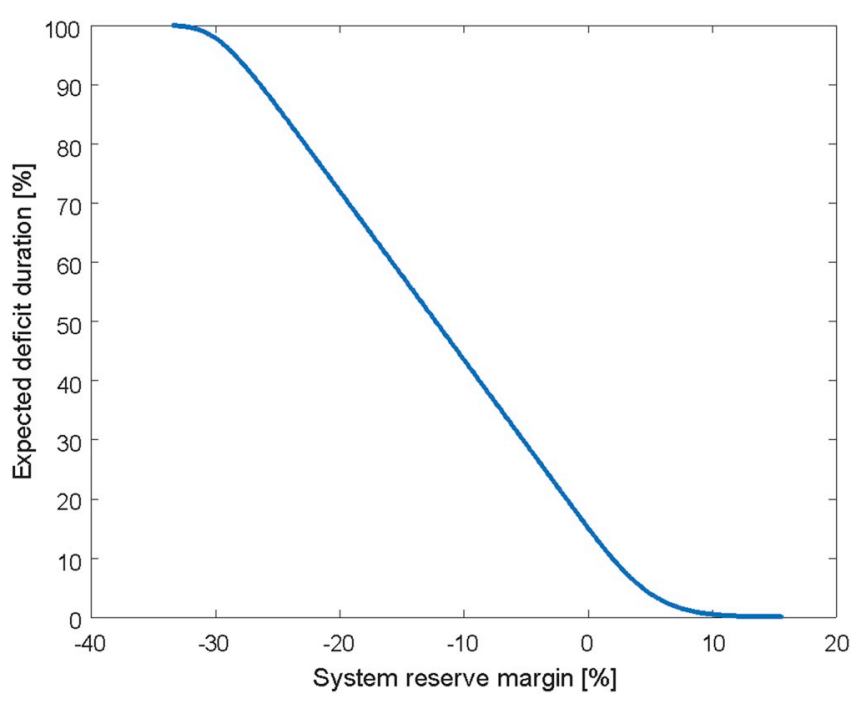

Fig. 3. Expected load curtailment duration as a function of the system reserve margin (Olsina et al., 2006). 
[MW]. This can be formulated as:

$K_{i}^{\text {bid,new }} t \quad a \cdot q \cdot K_{i} t$

where $a$ is the bidding factor (dimensionless) for new capacity. In this work, a bidding factor of $10.12 \%$ is assigned to each technology. Likewise, the expected availability of new power plants is denoted by $q$, which is introduced in Section 2.3.1.

The bid price for both existing and new capacity is endogenously determined based on the notion of expected "missing money" from energy profits. Thus, investors need to assess their profitability expectations against avoidable costs. These expectations depend upon revenues that would come from both the energy-only and the capacity market. First, the expected revenues coming from the energy-only market can be associated to the long-term spot price. By rearranging Eq. (15), the expected value of revenues coming from the spot market over 1 year, $\pi_{E M}$ [€/MW·year], can be defined as:

$\pi_{E M} \quad \int_{0}^{1} P D C \cdot d D$

Hence, each generator would offer capacity at a price at least equal to the difference between the expected revenues and its avoidable costs. If the expected spot price is higher than its avoidable costs, a rational investor would then bid zero on the capacity market. Conversely, if the expected spot price is lower than the costs, the investor need to bid the difference in order to recover entirely its avoidable costs.

For existing capacity, the avoidable costs are mainly the variable fuel costs. By knowing the marginal generation cost, $\overline{M C}_{i j} t[€ / \mathrm{MWh}]$, the bid price for 1 existing MW from vintage $j$ of technology $i$ at time $t$, $\pi_{i j}^{\text {bid,old }} t$ [€/MW·year], can be then formulated as:

$\pi_{i j}^{\text {bid,old }} t \quad \max \overline{M C}_{i j} t \cdot 8760 \quad \pi_{E M} t ; 0$

For new capacity, avoidable costs are increased by capital costs. In order to determine the bid price, an NPV-based method is employed. As referred by Hary et al. (2016), since the capacity market price will be guaranteed for only one year, investors then need to bid the difference between their investment costs and the present value of the expected stream of operating profits to come from the energy-only market over the amortization time of new power plants. For each technology, the expected total discounted cash flow due to energy rents is given by Eq. (18). By assuming the investment costs of technology $i, I C_{i} t[€ / \mathrm{MW}]$, the unitary bid price of new capacity, $\pi_{i}^{\text {bid,new }} t[€ / \mathrm{MW} \cdot$ year], can be thus determined by:

$\pi_{i}^{\text {bid,new }} t \quad \max \left[I C_{i} t \quad T P_{\bar{T}_{i}^{A}} t ; 0\right]$

After endogenously defining quantities and prices for capacity bids, the system administrator (or regulator) can set a target installed capacity, $K_{I}^{*} t$ [MW], as the demand curve for the capacity market. This curve can be defined instantly as a function of peak demand, $L_{\max } t$, jointly with a target reserve margin, $R M^{*}$. This can be expressed by:

$K_{I}^{*} t \quad L_{\max } t \cdot 1 \quad R M^{*}$

Here, the target reserve margin is related to the initial reserve margin, obtained by computing the optimal technology mix at the beginning of simulations. Moreover, this value is fix over the whole simulation horizon, seeking to avoid the influence of external sources of dynamics. A price cap is also set in order to completely define the demand curve for the capacity market. This work adopts a price cap, $P_{\text {cap }}^{*}$, equal to $600,000 € / \mathrm{MW} \cdot$ year. By following the "missing money" approach, the bid price cap for the capacity market is, as well, adjusted according to the revenues coming from the energy market:

$P_{\text {cap }}^{a d j} t \quad P_{\text {cap }}^{*} \quad \pi_{E M} t$

Finally, a capacity market clearing price at time $t, \pi_{C M} t$
[€/MW·year], can be attained as the price associated to the cumulated bid capacity, $K_{\text {cum }}^{\text {bid }} t$, that equals or immediately exceeds the target installed capacity, $K_{I}^{*} t$ :

$E \pi_{C M} t \quad \pi K_{\text {cum }}^{\text {bid }} t \quad K_{I}^{*} t$

Fig. 4 depicts the exemplary clearing of a capacity market. It is worth to mention that, if the cumulated bid capacity were insufficient for surpassing the target capacity, the capacity market would be cleared at the price cap. Finally, the annual revenue that 1 MW from each technology will expect to make in the capacity market at any time, $\pi_{i}^{C M} t$ $[€ / \mathrm{MW} \cdot \mathrm{year}]$, can be approximated by:

$\pi_{i}^{C M} t \quad E \pi_{C M} t$

When joining power systems including a capacity market, generators might then obtain a total annual rent equal to the addition of Eq. (17) and Eq. (28). This additional revenue should be used in Eq. (18) for approximating the total operating profit to be expected over the investment amortization period. In this model, the current state of demand and capacity will drive the observed profit to come from the capacity market. Furthermore, stochastic expectations upon future demand and capacity growth will define the expected value of future profits to be perceived from the same market.

\subsubsection{Performance metrics}

In order to assess the behavior of system adequacy over the simulation period under the three remuneration schemes discussed in this paper, two metrics are adopted. Both metrics seek to denote the effectiveness and the efficiency of each capacity mechanism, respectively.

First, the Root Square Mean Error (RSME) [\%] to the optimal reserve margin can be given by the following expression:

$R S M E \quad \sqrt{\frac{1}{S}} \cdot \sum_{s 1}^{S} R M^{*} \quad R M s^{2}$

where $S$ is the number of simulation steps from beginning to end of the simulation period; $R M n$ is the reserve margin simulated for time step $s$, within the simulation horizon; and $R M^{*}$ denotes the optimal reserve margin. This variable is assumed as an effectiveness metric and can be understood as the mean deviation from the desired reserve margin over the period under analysis.

Second, the Hourly Unitary Surplus (HUS) [€/MWh] is regarded as an efficiency metric and can be defined as follows:

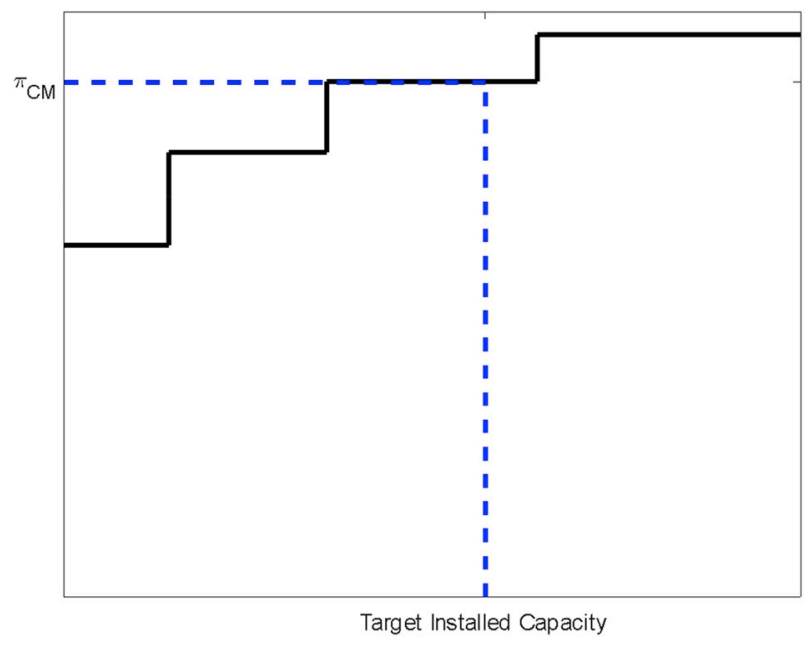

Fig. 4. Exemplary clearing of a capacity market. In black, the cumulated bids of new and existing capacity. 
HUS $\frac{1}{T} \cdot \int_{0}^{T} E M P t \quad P C t \cdot d t$

In Eq. (30), 0 and $T$ represent the initial and the final simulation time, respectively. In addition, $E M P t$ symbolizes the expected clearing price in the spot market; and $P C t$ denotes the average system production cost, at time $t$ within the simulation horizon. This parameter can be obtained from the enclosed area between simulations of expected market price and production cost. The HUS can be seen as the mean value of the hourly operating profits to be achieved by 1 MW of a generic generating unit over the simulation period. Operating profits are allocated mainly to cover the fixed investments costs of power plants. By assuming identical capital costs for each case study, a higher HUS would mean that investors perceive higher profits when including capacity mechanisms due to the higher energy prices being paid by consumers. When high enough, these profits would exceed the amount required to cover the average investment cost of generating units, turning into a net surplus for investors, in detriment of the economic efficiency of the electricity market.

\section{Simulations and results}

\subsection{Model pre-conditioning}

In order to assess the long-term system dynamics with the capacity remuneration mechanisms discussed in this work, simulations were carried out over a time horizon covering 20 years. These simulations involve the thermal generation system described in the previous section. The dde23 function of MATLAB was used to solve the delay differential equations (DDE) that describe the market dynamics. At $t \quad 0$, the simplified system comprises an energy mix resting in long-run economic equilibrium. Parameters describing the attributes of each generating technology are presented in Table 1. Likewise, information on the investment responsiveness functions for each technology is included in Table 2. Input data regarding the stochastic processes that describe the uncertainty on the development of power demand, system capacity and fuel prices are shown in Table 3. Finally, analytical expressions used to estimate the progress of thermal efficiencies for the considered generating technologies are included in the Appendix.

\subsection{Base case results}

Fig. 5 illustrates the simulation of the total installed capacity and the expected peak demand, alongside with the system reserve margin under the theoretical framework of ROA for replicating investors' decisionmaking. This simulation considers profits coming solely from the energy-only market, and thus coincide with results presented by Rios et al. (2019). Here, the market behavior accounts for the occurrence of

Table 1

Input data on the generation technologies composing the test supply system.

\begin{tabular}{|c|c|c|c|}
\hline Technology & $\mathrm{HC}$ & CC & GT \\
\hline Initial capacity $\left(K_{i}\right)$ at $t \quad 0[\mathrm{MW}]$ & 11905 & 2540 & 2020 \\
\hline Construction delay $\left(\underline{T}_{i}^{C}\right)[$ month $]$ & 36 & 18 & 9 \\
\hline Lifetime $\left(T_{i}\right)$ [year] & 40 & 30 & 20 \\
\hline Investment costs $\left(I C_{i}\right)[€ / \mathrm{kW}]$ & 1000 & 600 & 300 \\
\hline Amortization period $\left(\underline{T}_{i}^{A}\right)$ [year] & 25 & 20 & 15 \\
\hline Discount rate $(\rho)[\% /$ year $]$ & 12.5 & 12.5 & 12.5 \\
\hline Time to the Option Maturity $(d t)$ [year] & 1.0 & 1.0 & 1.0 \\
\hline Risk-free rate $(\phi)[\% /$ year $]$ & 12.5 & 12.5 & 12.5 \\
\hline Fixed costs $[€ / M W h]$ & 14.92 & 9.33 & 5.06 \\
\hline Fuel price $\left(F P_{i}\right)[€ / \mathrm{MWh}]$ & 6.50 & 10.50 & 10.50 \\
\hline Efficiency (age structure at $t$ & 0.4063 & 0.4625 & 0.3072 \\
\hline Usage duration $\left(D_{i}\right)$ (at $t$ & 0.8345 & 0.3723 & 0.0052 \\
\hline Unit availability $(q)$ (at $t$ & 0.9096 & 0.9096 & 0.9096 \\
\hline
\end{tabular}

Table 2

Input data on the functions (Eq. (3)) describing the investment responsiveness for each technology.

\begin{tabular}{llll}
\hline Technology & HC & CC & GT \\
\hline Saturation $\left(\mathrm{im}_{i}^{\max }\right)$ & 1.5 & 3.0 & 2.0 \\
Alpha $\left(\alpha_{i}\right.$ & 3.5 & 2.0 & 2.5 \\
Beta $\left(\beta_{i}\right.$ & 2.8069 & 2.6932 & 2.5000 \\
\hline
\end{tabular}

Table 3

Input data on the stochastic processes describing uncertainty on power demand, capacity and fuel prices at the Option Maturity.

\begin{tabular}{lllll}
\hline Parameter & $g_{L}$ & $g_{K}$ & $g_{F P}^{\text {coal }}$ & $g_{F P}^{\text {gas }}$ \\
\hline Long-term growth rate $(\underline{g})[\% /$ year] & 1.00 & 1.00 & 0.02 & 0.02 \\
Speed of reversion $(\eta)$ [\%/year] & 50.0 & 50.0 & 50.0 & 50.0 \\
Volatility $(\sigma)$ [\%/year] & 2.00 & 2.00 & 1.85 & 3.95 \\
Correlation factor [dmnl] & 0.80 & 0.80 & 0.70 & 0.70 \\
\hline
\end{tabular}

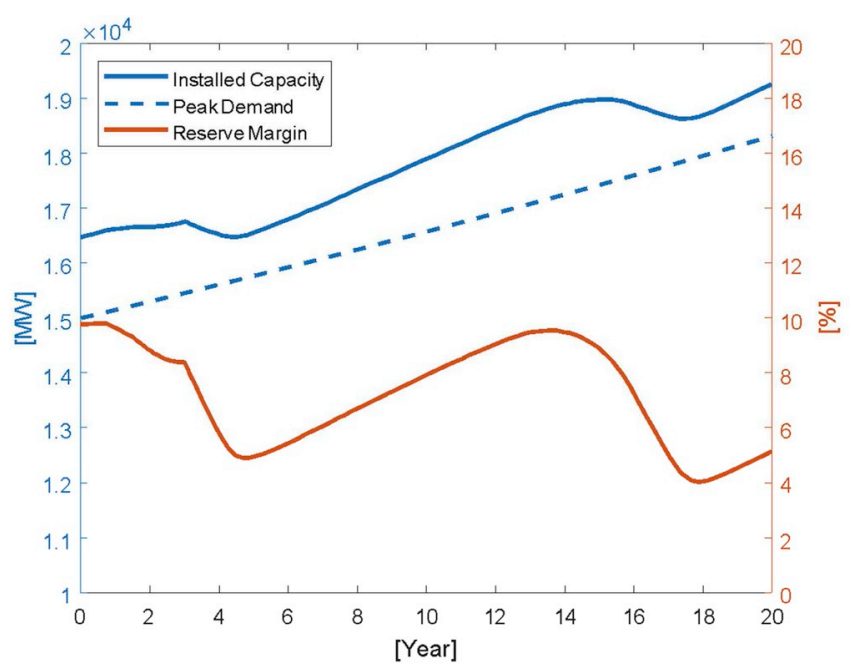

Fig. 5. Simulation of capacity adequacy in an energy-only market based on the investment decision-making under irreversibility and uncertainty (Rios et al., 2019)

construction cycles, which is explained in terms of the description of profitability expectations based on the dynamic interaction of observed market conditions (i.e. the $\mathrm{EV}$ ) and the wait-and-see flexibility (i.e. the $\mathrm{CV}$ ). It is worth to note that such underlying model has been validated in the scope of the SD modeling approach by following the formal procedure proposed by Barlas (1996).

Now, the simulation of future dynamics of the reserve margin under capacity incentives is shown in Fig. 6. These economic incentives involve a price-based mechanism, i.e. a capacity payment, and a quantity-based mechanism, i.e. a capacity market, both of which have been explained in Section 2.3. As in the base case, the reserve margins in Fig. 6 are associated to a construction cycle. Occurrence of construction cycles, despite the addition of investment incentives, can be explained in sight of the expectation formation of investors. At the start of simulations, uncertainty in load and capacity growth allows to anticipate some scenarios conditioned by deficit expectations higher than observed. Such situations are critical for incrementing the expected value of future capacity payments, and thus helps in increasing the $\mathrm{CV}$ of new power plants. Only when a high deficit probability is observed (around year 5), the addition of major profits during capacity shortfall situations and capacity payments trigger an EV capable of outweighing the value of postponement, and therefore new power plants enter the system. 


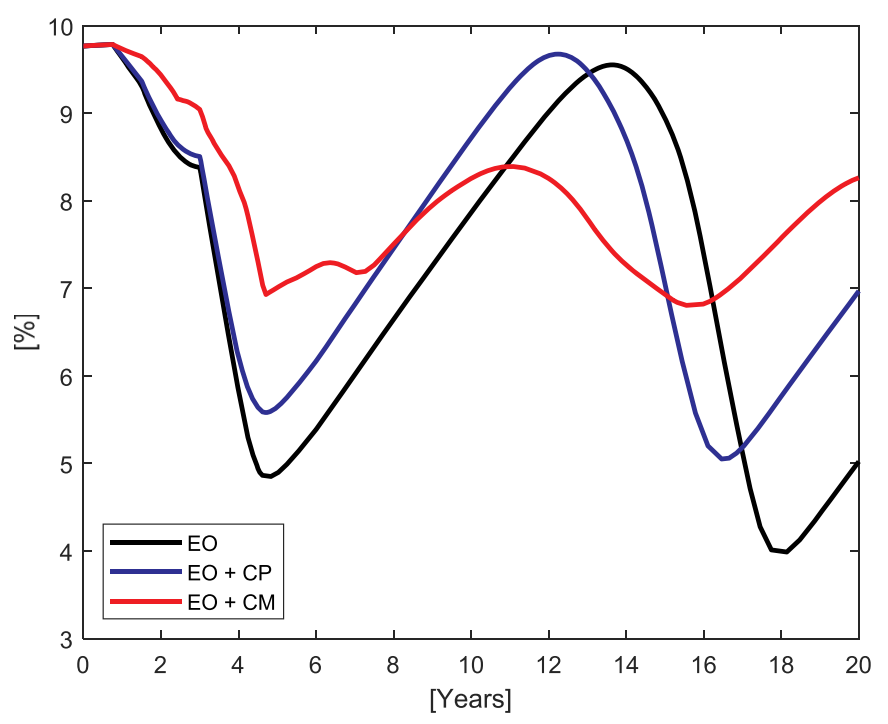

Fig. 6. Simulation of reserve margin in an energy-only (EO) market; EO plus capacity payments (EO $\mathrm{CP}$ ); and EO plus capacity market (EO CM).

When dealing with a capacity market, the outcome is quite similar. Here, expectations upon market conditions after the beginning of simulations define scenarios with reserve margins higher than observed. These scenarios are associated to lower revenues that would come from the energy-only market, and thus higher bid prices in the capacity market. Moreover, it has been found that, for an increase of reserve margins in the short run (e.g. the Option Maturity), the bid prices increase at a higher rate than the bid capacity with respect to the target capacity. Hence, despite expectations upon situations with higher reserve margins, the capacity market would be expected to be cleared at a similar level of cumulated bid capacity. At the Option Maturity, this determines realizations of capacity market clearing prices higher than observed, which ultimately aids to upturn the expected value of potential profits derived from such market. Consequently, the CV of new investments is incremented, and new projects are postponed until the reserve margin reaches a significant low value around year 4 . Only then, the shortfall of installed capacity with respect to its target allows observing higher profits from the capacity market. These profits, added to the higher profits related to capacity shortfalls coming from the energy-only market, sets the EV higher than the $\mathrm{CV}$, thus enabling construction of new power plants.

Despite the occurrence of construction cycles, Fig. 6 shows that reserve margins would depict a reduced amplitude due to the integration of capacity mechanisms. It is worth to note the steadier oscillation being depicted by the reserve margin with a capacity market. Such behavior can be explained because investors have to balance expectations upon profits coming from the energy market (related to lower reserve margins and the deferral option) against profits coming from the capacity market (related to higher reserve margins and the exercise of new investments). Notwithstanding, this oscillation tends to occur around values (7\%-8\%) lower than the target reserve margin $(9.75 \%)$. Ultimately, this outcome depends upon the interaction of the variables and parameters that determine each source of profit. On one hand, the energy rents are mainly deficit profits, which are defined by the VOLL. On the other hand, the capacity market revenues are contingent upon the bid factor of new capacity and the price cap.

In accordance the reduced amplitude of reserve margins, as seen in Fig. 7, expectations upon capacity shortfall events would be dampened when including incentives, thus supporting the security of supply. In those cases, such system behavior can be attributed to the upturn of the $\mathrm{EV}$ of power plants thanks to the addition of a new source of profit for investors. Unlike the situation with the energy-only market, the

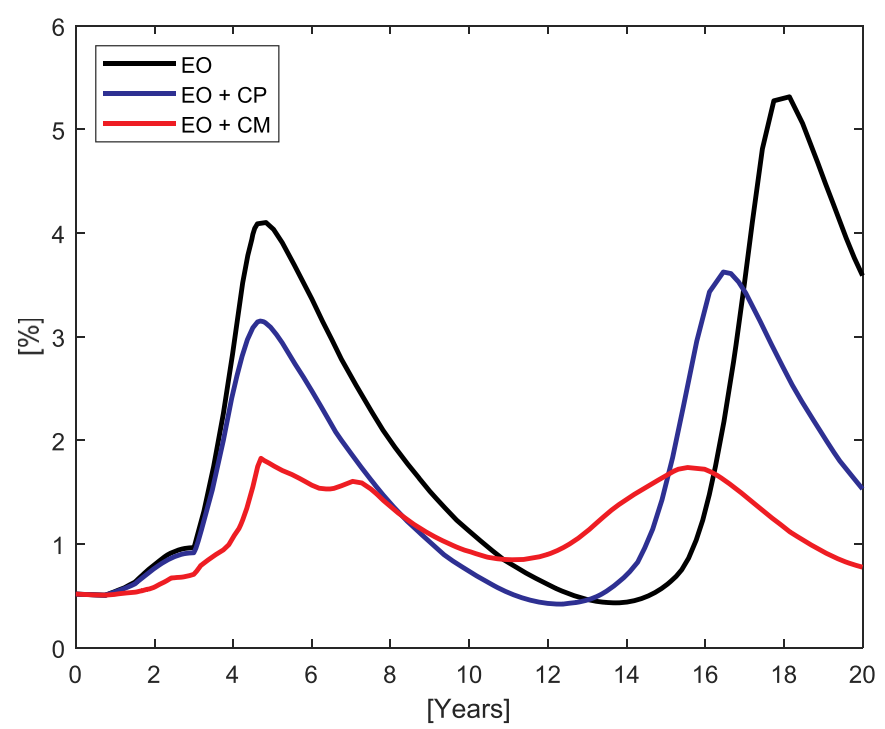

Fig. 7. Simulation of expected deficit duration in an energy-only (EO) market; EO plus capacity payments (EO CP),; and EO plus capacity market (EO CM).

evolution of the PI with capacity mechanisms is thus associated to the First and Second Strategies within the Exercise-Continuation Value plane (Invest Now and Probably Later in Fig. 2, respectively). This is critical for the baseload technology, which accounts for the higher capital costs, and thus is assumed to adopt the most-risk-averse profile when deciding new power plants. In that context, Fig. 8 displays the evolution of capacity under construction for the baseload technology under the three discussed market designs. By looking at Fig. 8, it can be seen that the capacity under construction depicts a more stable response around the expected behavior under long-term economic equilibrium when including capacity mechanisms.

The more stable development with capacity mechanisms would be obtained at expense of higher prices for consumers. Fig. 9 includes the simulation of total energy prices with the integration of capacity incentives. Regarding results from Fig. 7, the energy-only market in those cases would account for lower prices due to the reduced durations of deficit. However, the prevailing capacity incentives would increase the total energy price to be paid by users, and thus the benefit to be

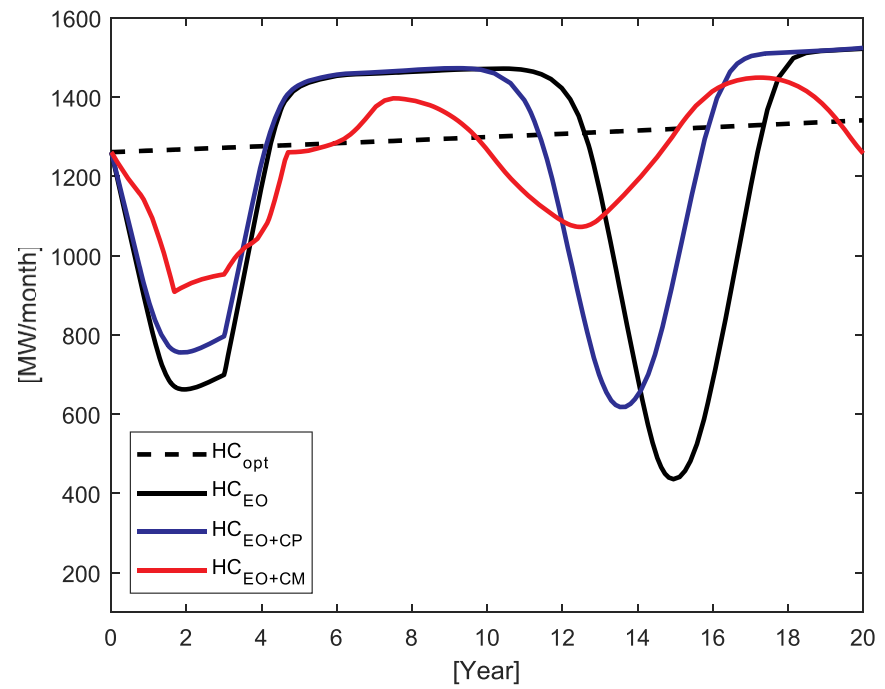

Fig. 8. Simulation of capacity under construction (Kuc) for the base technology (HC) in an energy-only (EO) market; EO plus capacity payments (EO CP); and EO plus capacity market (EO CM). 


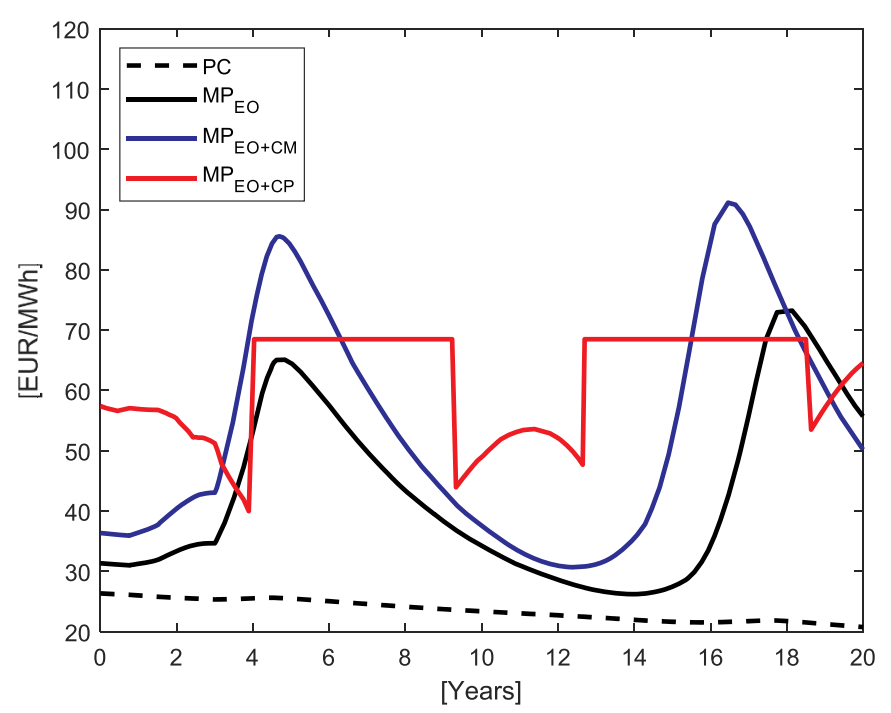

Fig. 9. Simulation of average production cost (PC) and market price (MP) in an energy-only (EO) market; EO plus capacity payments (EO CP); and EO plus capacity market (EO CM).

perceived by investors. When dealing with capacity payments, the price would account for major spikes, coincident to the reductions of reserve margin. This is reasonable, since the capacity payment is assumed proportional to the expected deficit duration and the VOLL. The total price in the context of the capacity market would denote a slighter fluctuation. However, its average value over the simulation period would be increased due to the addition of the capacity market price.

By looking at Fig. 9, it can be seen how the total price in the context of the capacity market decreases rapidly after the beginning of simulations. This occurs despite the increase of the spot market, due to the reduction of the system reserve margin (Fig. 6). This is explained in sight of a more dramatic decrease of the capacity market clearing price with respect to the spot market price. It is worth to recall that, based on the "missing money", bid prices in the capacity market denote the difference between avoidable costs and expected revenues from the energy market. Hence, bid prices, and consequently, the capacity market clearing price, plummet as a result of the increase of the spot market price. Only after the reserve margin decreases low enough around year 4, the cumulated bids of existing and new capacity are insufficient to cover the target capacity, and therefore the capacity market is cleared at the price cap. This price cap prevails until sufficient capacity is constructed, after which the construction cycle would be triggered once again.

Rigorously, a trade-off can be identified in terms of the mean deviation from the target reserve margin (effectiveness and security of supply) against the hourly-average unitary surplus for investors (efficiency and cost for consumers). Table 4 summarizes the performance metrics delivered by the three market designs under study. By considering the test generation system, the integration of a capacity market provides the best performance regarding the security of supply, at expense of the highest cost for consumers. On the opposite, the energyonly market allows the lowest cost, in detriment of the worst security of supply. The trade-off can also be explained in terms of the higher perception of profitability, associated to higher power prices, needed to

Table 4

Performance metrics of simulated capacity adequacy in an energy-only (EO) market, EO plus capacity payments (EO $\mathrm{CP}$ ) and EO plus capacity market (EO $\mathrm{CM})$.

\begin{tabular}{|c|c|c|c|c|}
\hline Performance metric & $\mathrm{EO}$ & EO CP & $\mathrm{EO}$ & $\mathrm{CM}$ \\
\hline RSME to Target reserve margin [\%] & 2.61 & 2.37 & 1.79 & \\
\hline HUS for investors $[€ / \mathrm{MWh}]$ & 19.24 & 30.29 & 38.32 & \\
\hline
\end{tabular}

counteract the investor's willingness to postpone new power plants and promote a steadier capacity adequacy.

\subsection{Impact of uncertainty on the performance of system adequacy}

A sensitivity analysis was carried out with respect to the growth rate volatility of load and capacity. According to the scope of our study, these are considered to be the key parameters driving the uncertainty that affects the decision-making of new generating capacity. Because of that, such results are the most significant for assessing the model long-term response.

Simulation results for a lower and a higher volatility of load growth and capacity construction related to the base case are included in Fig. 10 and Fig. 11, respectively. As exposed by Rios et al. (2019), the long-term dynamics of electricity markets would be extremely sensitive to this parameter when investors account for the postponement option of new power plants under irreversibility and uncertainty. From the initial equilibrium state, the capacity adequacy would face a higher decline of reserve margins when investors expect a higher volatility. At the same time, significant price spikes would be affecting the energy-only market. Despite the system behavior would eventually stabilize, it would derive in a reduced level of reserve margin with respect to the initial (optimal) value, thus increasing the prevailing level of prices in the marketplace. This behavior is explained in terms of the expectation formation of investors, since the more volatile expectations upon load and capacity at option maturity result in realizations with higher scarcity rents with respect to the base case. This allow the $\mathrm{CV}$ to escalate, therefore limiting the addition of new generating units even more. Ultimately, investors require experiencing higher profits, i.e. a higher $\mathrm{EV}$, associated to more severe capacity shortage situations, in order to decide construction of new power plants.

Results from Figs. 10 and 11 show how the addition of capacity incentives, especially the capacity market, would allow the market to obtain a smaller reduction of reserve margins after the start of simulations, and an overall more stable long-term behavior with respect to the energy-only market. This aspect should be critical for markets facing highly uncertain growth rates, e.g. in developing countries with fastgrowing emerging economies. In that sense, the integration of capacity mechanisms might contribute to mitigate or avoid the occurrence of construction cycles, thus increasing the security of supply. However, when implementing such mechanisms, it would be worth to remind the trade-off involving the increase of supply security and the increase of

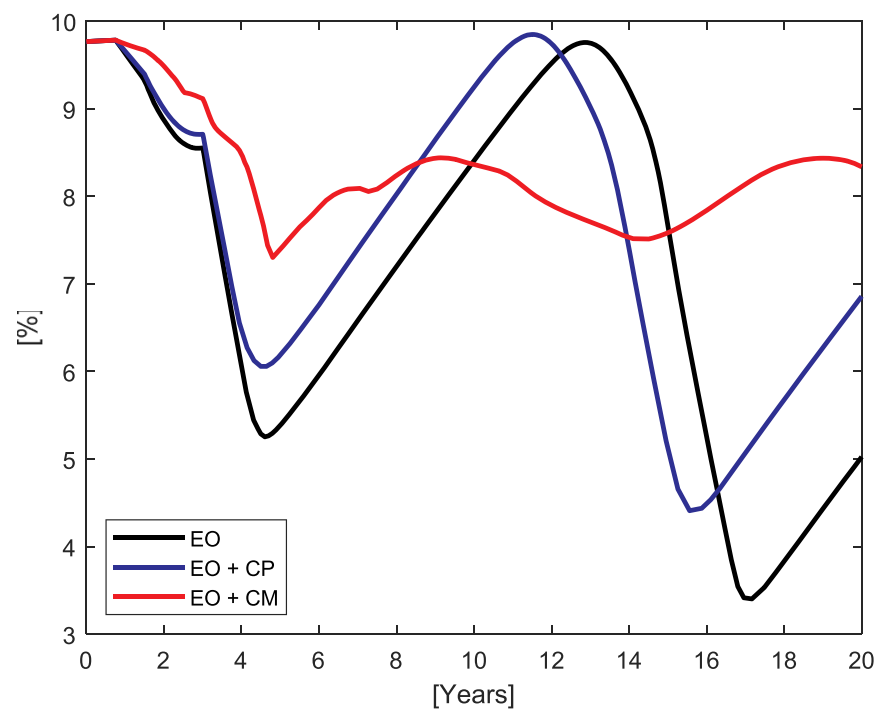

Fig. 10. Reserve margin in an energy-only (EO) market; EO plus capacity payments (EO CP); and EO plus capacity market (EO CM); with the growth rate volatility of demand and capacity equal to $1.5 \%$ /year. 


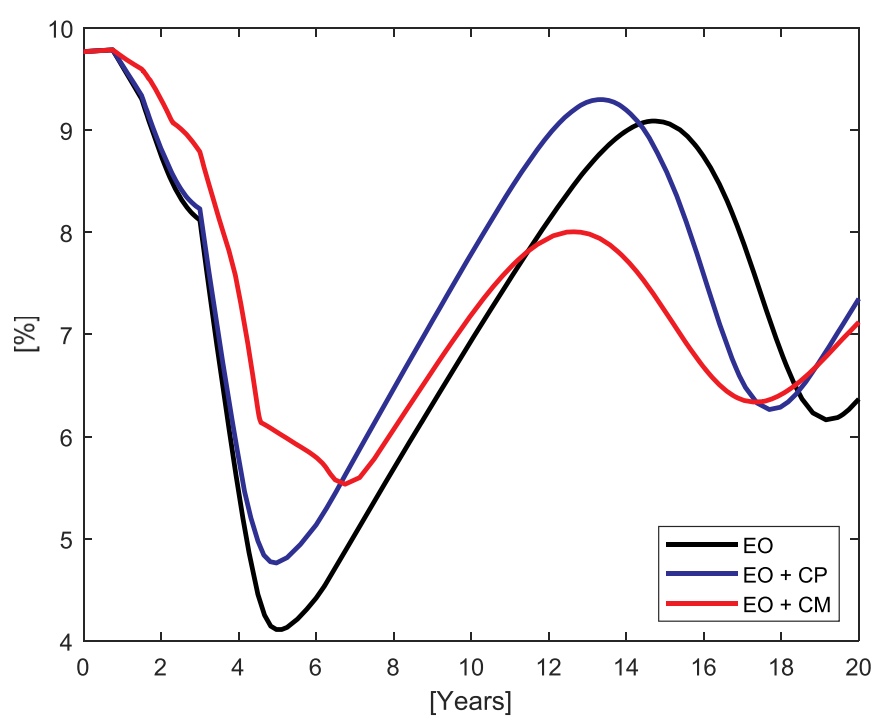

Fig. 11. Reserve margin in an energy-only (EO) market; EO plus capacity payments (EO $\mathrm{CP}$ ); and EO plus capacity market (EO $\mathrm{CM}$ ); with the growth rate volatility of demand and capacity equal to $3 \% /$ year.

total energy price to be paid by consumers.

\section{Conclusions and policy implications}

This article has introduced a modeling framework intending to assist in the evaluation of remuneration incentives to power capacity by realistically describing the microeconomics of the decision-making process followed by generators under irreversibility and uncertainty. This work has built upon a recent-developed simulation model that assesses the long-term dynamics of the energy-only market based on an investment signal computed by means of ROA, thus contingent upon the $\mathrm{EV}$ and the $\mathrm{CV}$ of new power plants. In that context, the main contribution of this work has been to address the long-run power system performance with the introduction of two capacity remuneration mechanisms. The examined incentives involve both, a price-based mechanism, i.e. a capacity payment, and a quantity-based remuneration mechanism, i.e. a capacity market. The question about the effectiveness and efficiency of these capacity mechanisms has been at the center of the debate in recent years. In fact, this issue is under permanent scrutiny in electricity markets worldwide since there are yet limited theoretical and empirical answers regarding their economic implications and overall impact on the long-term security of supply.

Simulations were carried out on a test generation system by considering three market designs: an energy-only market, an energy market plus capacity payments, and an energy-market plus a capacity market. Results have suggested that the integration of capacity incentives, especially the capacity market, would allow the system to develop a steadier behavior in the long term, thus limiting the occurrence of construction cycles. In general, this finding is coincident with conclusions of very recent research papers addressing the same topic (Petitet et al., 2017; Abani et al., 2018; Alvarez-Uribe et al., 2018; Heidarizadeh and Ahmadian, 2019). This work has deepened the analysis by explicitly modeling the decision-making of investors under irreversibility and uncertainty. In addition, the extent to which capacity mechanisms are effective and efficient in the long-term have been addressed by formally introducing two performance metrics. These metrics have permitted to identify a trade-off between effectiveness and efficiency, which means that the incorporation of incentives would certainly allow to achieve a steadier system development, but, at expense of higher energy costs for consumers.

Governmental authorities and regulators might benefit from the proposed structural power market model and performance metrics in order to gain insight on the designing of efficient electricity markets that deliver supply reliability. According to the scope of this article, the capacity market has looked preferable for promoting capacity adequacy in response to demand growth. A sensitivity analysis has suggested that the capacity market would also contribute in increasing supply security when higher uncertainties affect growth of key market variables, i.e. electricity demand and power capacity, as it is indeed the case in fastgrowing emerging economies. This is consistent with the worldwide inclination to introduce quantity-based capacity mechanisms for remunerating generation capacity. The proposed modeling framework offers a tool to address policy and economic implications of different mechanism designs, that is, the higher energy prices associated to achieving a steadier system long-run evolution. It is worth to recall that such higher prices increase the value of immediate exercising construction of new generation projects, thus counteracting the generators' preference to postpone irreversible investments under uncertainty.

\subsection{Critical review of the proposed model and further research}

This work is limited to the consideration of only two capacity incentives. It is worth to recognize the existence of further mechanisms, some of which are listed in Section 1. Design and application of such mechanisms varies according to the specific power market itself. Here, simulations of the capacity market have adopted a constant bidding factor of new capacity ( $a$ ) over the entire horizon. It is worth to note that a sensitivity analysis on $a$ would offer a more refined insight about its impact on the system response. Moreover, the dynamic adjustment of $a$ might provide an additional tool to control the system behavior over the long-term. However, the constant value of $a$ is assumed to be sufficient as a first approach to analyze the long-term system dynamics. With that in mind, the two incentives discussed in this article, jointly with their parameters, mainly intend to demonstrate the applicability of the proposed approach. The underlying model is flexible enough to allow the integration of alternative, tailor-made mechanisms.

The impact of renewable generation technologies and demand responsiveness is also beyond the scope of this work. It is important to mention the current role of large-scale addition of renewables in power markets worldwide. Moreover, the integration of smart-grid technologies, e.g. energy storage, tough incipient, is allowing the demand to be much more responsive against price fluctuations. The literature includes the application of System Dynamics approach to describe the market dynamics with renewables (Hasani-Marzooni and Hosseini, 2011b). In order to define investor's long-term expectations upon profitability, the challenge consists in adapting the long-term equivalents of load and supply to account for the chronological pattern of renewable power output. In this work, renewable integration will indeed introduce a new source of short-term and long-term uncertainty, which in turn will be critical for the investment decision-making model based on Real Options. On one hand, short-term stochastic power fluctuations of renewable generation would increase the need for incremental and decremental operating reserve capacity in conventional generating units. As energy and reserve markets are coupled, increasing demand for reserve will affect reserve and energy prices as well. On the other hand, future penetration rates of renewable capacity to existing supply systems reduce the net demand to be supplied to the conventional technologies, particularly base-load capacity. This entails a significant source of uncertainty when deciding expansion in conventional thermal technologies. A stochastic logistic diffusion model (Verhulst-Pearl process) has been proposed for describing uncertainty dynamics of renewable penetration rates in the context of Real Option valuation (Blanco and Olsina, 2011). These phenomena are amenable to be incorporated in the proposed long-term market simulation model.

However, this work first seeks to evaluate the market evolution with capacity mechanisms according to the prevailing technology mix, i.e. thermal technologies. Furthermore, it is assumed that such mix will prevail in the majority of power markets, even in the long run (Covert 
et al., 2016). Because of that, renewable integration and demand responsiveness involve an important research problem to be undertaken in further projects.

\section{Acknowledgements}

This work was supported by the PRONII program of the Paraguayan
National Council of Science and Technology (CONACYT); and the Argentinean National Agency for Promotion of Science and Technology (ANPCyT) [PICT-2014-1610].

\section{Appendix}

Polynomial estimation of thermal efficiencies $\left(t>t_{0}\right.$ and $t_{0}$

$\mathrm{HC}$ :

$\mathrm{CC}$

GT:

$\begin{array}{llll}1.5684 e & 24 t^{4} & 6.2935 e & 22 t \\ 3.2150 e & 11 t^{4} & 1.9290 e\end{array}$

$22 t^{3}$

$6.2014 e$

$20 t^{2}$

$1.6667 e$

2000) ( $t$ in months)

$3.2150 e \quad 11 t^{4} \quad 1.92$

1.9290

\section{$08 t^{3} \quad 4.0509 e \quad 06 t^{2} \quad 5.1389 e$}

$08 t^{3} \quad 4.7454 e \quad 06 t^{2} \quad 7.2222 e \quad 04 t$
$04 t \quad 0.455$

0.600

0.350

\section{References}

Abani, A.O., Hary, N., Rious, V., Saguan, M., 2018. The impact of investors' risk aversion on the performances of capacity remuneration mechanisms. Energy Policy 112, 84-97.

Ahmad, S., Tahar, R.M., Muhammad-Sukki, F., Munir, A.B., Rahim, R.A., 2016. Application of System Dynamics approach in electricity sector modelling: a review. Renew. Sustain. Energy Rev. 56, 29-37.

Allan, R.N., Navarro Sanchez, H., 2004. Uncertainty considerations in the pool purchase price in the England and Wales electricity supply industry. IEE Proc. Gener. Transm. Distrib. 141 (2), 125-132.

Alvarez-Uribe, K., Arango-Aramburu, S., Larsen, E., 2018. Forward contracts in electricity markets and capacity investment: a simulation study. Util. Policy 54, $1-10$.

Arango, S., Larsen, E., 2011. Cycles in deregulated electricity markets: empirical evidence from two decades. Energy Policy 39 (5), 2457-2466.

Assili, M., Javidi, H., Ghazi, R., 2008. An improved mechanism for capacity payment based on System Dynamics modeling for investment planning in competitive electricity environment. Energy Policy 36 (10), 3703-3713.

Barlas, Y., 1996. Formal aspects of model validity and validation in system dynamics. Syst. Dyn. Rev.: J. Syst. Dynam. Soc. 12 (3), 183-210.

Battle, C., Rodilla, P., 2010. A critical assessment of the different approaches aimed to secure electricity generation supply. Energy Policy 38 (11), 7169-7179.

Blanco, G., Olsina, F., 2011. Optimal decision-making under uncertainty - application to power transmission investments. In: I. Dritsas, Stochastic Optimization - Seeing the Optimal for the Uncertain. InTech, Rijeka, HR, pp. 107-140.

Blanco, G., Olsina, F., Garces, F., 2012. Transmission investments under uncertainty: the impact of flexibility on decision-making. In: 2012 IEEE Power and Energy Society General Meeting, pp. 1-8 (San Diego, US).

Brosch, R., 2001. Portfolio-aspects in Real Options Management. Department of Finance, Johann Wolfgang von Goethe - University Frankfurt am Main, Frankfurt am Main, DE.

Bublitz, A., Keles, D., Zimmermann, F., Fraunholz, C., Fichtner, W., 2019. A survey on electricity market design: insights from theory and real-world implementations of capacity remuneration mechanisms. Energy Econ. https://doi.org/10.1016/j. eneco.2019.01.030.

Bunn, D., Larsen, E., 1992. Sensitivity of reserve margin to factors influencing investment behavior in the electricity market of England and Wales. Energy Policy 20 (5), 420-429.

Bunn, D., Larsen, E., 1994. Assessment of the uncertainty in future UK electricity investment using an industry simulation model. Util. Policy 4 (3), 229-236.

Caramanis, M., 1982. Investment decisions and long-term planning under electricity spot pricing. IEEE Trans. Power Apparatus Syst. 12, 4640-4648.

Caramanis, M., Bohn, R., Schweppe, F., 1982. Optimal spot pricing: practice and theory. IEEE Trans. Power Apparatus Syst. (9), 3234-3245.

Chuang, A., Wu, F., 2000. Capacity payments and the pricing of reliability in competitive generation markets. In: 33th Hawaii International Conference on System Sciences (HICS), vols. 1-7. Maui, USA. HI.

Copeland, T., Antikarov, V., 2003. Real Options, Revised Edition. A Practioners Guide (New York, US: Texere).

Covert, T., Greenstone, M., Knittel, C., 2016. Will we ever stop using fossil fuels? J. Econ. Perspect. 30 (1), 117-138.

de Vries, L., Heijnen, P., 2008. The impact of electricity market design upon investment under uncertainty: the effectiveness of capacity mechanisms. Util. Policy 16 (3), 215-227.

DECC, 2014. Implementing Electricity Market Reform. Department of Energy and Climate Change, London, UK.

Dixit, A., Pindyck, R., 1994. Investment under Uncertainty. Princeton university press, Princeton, US.

Eager, D., Bialek, J., Johnson, T., 2010. Validation of a dynamic control model to simulate investment cycles in electricity generating capacity. In: 2010 IEEE Power and Energy Society General Meeting, pp. 1-8 (Minneapolis, US).

Eager, D., Hobbs, B., Bialek, J., 2012. Dynamic modeling of thermal generation capacity investment: application to markets with high wind penetration. IEEE Trans. Power Syst. 27 (4), 2127-2137.

Ford, A., 1999. Cycles in competitive electricity markets: a simulation study of the western United States. Energy Policy 27 (11), 637-658.

Gillespie, D., 1996. Exact numerical simulation of the Ornstein-Uhlenbeck process and its integral. Phys. Rev. 54 (2), 2084-2091.

Hary, N., Rious, V., Saguan, M., 2016. The electricity generation adequacy problem: assessing dynamic effects of capacity remuneration mechanisms. Energy Policy 91, $113-127$.

Hasani-Marzooni, M., Hosseini, S., 2011a. Dynamic assessment of capacity investment in electricity market considering complementary capacity mechanisms. Energy 36 (1), 277-293.

Hasani-Marzooni, M., Hosseini, S., 2011b. Dynamic model for market-based capacity investment decision considering stochastic characteristic of wind power. Renew. Energy 36 (8), 2205-2219.

Hasani-Marzooni, M., Hosseini, S., 2013. Dynamic analysis of various investment incentives and regional capacity assignment in Iranian electricity market. Energy Policy 56, 271-284.

Heidarizadeh, M., Ahmadian, M., 2019. Capacity Certificate Mechanism: a step forward toward a market based generation capacity incentive. Energy. https://doi.org/ 10.1016/j.energy.2019.01.091.

Huang, M.-G., 2009. Real options approach-based demand forecasting method for a range of products with highly volatile and correlated demand. Eur. J. Oper. Res. 198 (3), 867-877.

Ibanez-Lopez, A.S., Martinez-Val, J.M., Moratilla-Soria, B.Y., 2017. A dynamic simulation model for assessing the overall impact of incentive policies on power system reliability, costs and environment. Energy Policy 102, 170-188.

Kadoya, T., Sasaki, T., Ihara, S., Larose, E., Sanford, M., Graham, A., Eubanks, C.K., 2005. Utilizing System Dynamics modeling to examine impact of deregulation on generation capacity growth. Proc. IEEE 93 (11), 2060-2069.

Leopold, A., 2015. Energy related system dynamic models: a literature review. Cent. Eur. J. Oper. Res. 24 (1), 231-261.

Longstaff, F.A., Schwartz, E.S., 2001. Valuing American options by simulation: a simple least-squares approach. Rev. Financ. Stud. 14 (1), 113-147.

Moreno, R., Barroso, L.A., Rudnick, H., Mocarquer, S., Bezerra, B., 2010. Auction approaches of long-term contracts to ensure generation investment in electricity markets: lessons from the Brazilian and Chilean experiences. Energy Policy 38 (10), 5758-5769.

Movahednasab, A., Rashidinejad, M., Abdollahi, A., 2017. A system dynamics analysis of the long run investment in market-based electric generation expansion with renewable resources. Int. Trans. Electr. Mach. Energy. Syst. 27 (8), 1-14.

Olsina, F., 2005. Long-term Dynamics of Electricity Markets. Ph.D. Dissertation. Institute of Electrical Energy (IEE), National University of San Juan, Argentina.

Olsina, F., Garces, F., Haubrich, H.-J., 2006. Modeling long-term dynamics of electricity markets. Energy Policy 34 (12), 1411-1433.

Olsina, F., Garces, F., 2008. Stochastic modeling of the long-term dynamics of liberalized electricity markets. In: 2008 IEEE Power and Energy Society General Meeting, pp. 1-6 (Pittsburgh, US).

Olsina, F., Pringles, R., Larisson, C., Garces, F., 2014. Reliability payments to generation capacity in electricity markets. Energy Policy 73, 211-224.

Osorio, S., van Ackere, A., 2016. From nuclear phase-out to renewable energies in the Swiss electricity market. Energy Policy 93, 8-22. 
Pereira, A., Saraiva, J., 2011. Generation expansion planning (GEP) - a long-term approach using system dynamics and genetic algorithms (GAs). Energy 36 (8), 5180-5199.

Pereira, A., Saraiva, J., 2013. A long term generation expansion planning model using System Dynamics - case study using data from the Portuguese/Spanish generation system. Electr. Power Syst. Res. 97, 41-50.

Petitet, M., Finon, D., Janssen, T., 2017. Capacity adequacy in power markets facing energy transition: a comparison of scarcity pricing and capacity mechanism. Energy Policy 103, 30-46.

Rios, D., Blanco, G., Olsina, F., 2019. Integrating Real Options Analysis with long-term electricity market models. Energy Econ. 80, 188-205.

Rios, D., Fernandez, F., Blanco, G., 2016. Analysis of power systems expansion processe based on System Dynamics - state-of-the-art. In: 2016 IEEE Biennial Congress of Argentina, pp. 1-6 (Buenos Aires, AR).
RTE, 2014. French Capacity Market: Report Accompanying the Draft Rules. FR: Reseau de transport d'electricite (RTE), Nanterre.

Sanchez, J.J., Barquín, J., Centeno, E., Lopez-Peña, A., 2008. A multidisciplinary approach to model long-term investments in electricity generation: combining System Dynamics, Credit-risk Theory and Game Theory. In: 2008 IEEE Power and Energy Society General Meeting, pp. 1-8 (Pittsburgh, US).

Schreiber, M., 2018. Capacity mechanisms: an intervention needed in failing markets? In: Mathis, K., Huber, B.R. (Eds.), Energy Law and Economics. Springer, Cham, pp. 211-237.

Sterman, J., 2000. Business Dynamics: Systems Thinking and Modeling for a Complex World. Irwin/McGraw-Hill, Boston, US.

Stoft, S., 2002. Power System Economics: Designing Markets for Electricity. IEEE/Wiley. Ventosa, M., Baíllo, A., Ramos, A., Rivier, M., 2005. Electricity market modeling trends. Energy Policy 33 (7), 897-913. 